SANDIA REPORT SAND82-0863 • Unlimited Release • UC-66c

Printed February 1983

I. 8810

\title{
Euler Buckling of Geothermal Well Casing
}

Robert P. Rechard, Karl W. Schuler

Prepared by

Sandia National Laboratories

Albuquerque, New Mexico 87185 and Livermore, California 94550

for the United States Department of Energy

under Contract DE-AC04-76DP00789

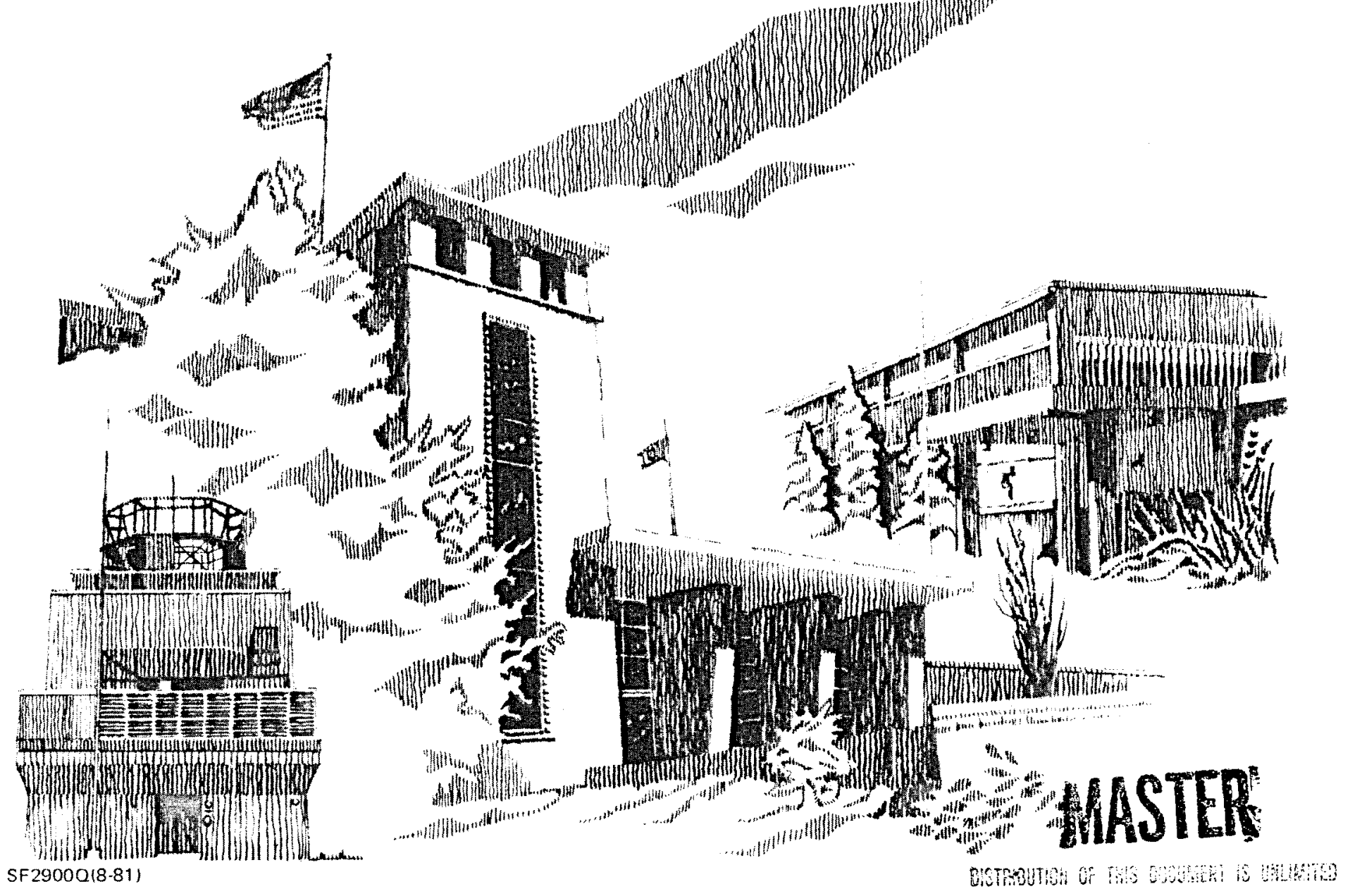




\section{DISCLAIMER}

This report was prepared as an account of work sponsored by an agency of the United States Government. Neither the United States Government nor any agency Thereof, nor any of their employees, makes any warranty, express or implied, or assumes any legal liability or responsibility for the accuracy, completeness, or usefulness of any information, apparatus, product, or process disclosed, or represents that its use would not infringe privately owned rights. Reference herein to any specific commercial product, process, or service by trade name, trademark, manufacturer, or otherwise does not necessarily constitute or imply its endorsement, recommendation, or favoring by the United States Government or any agency thereof. The views and opinions of authors expressed herein do not necessarily state or reflect those of the United States Government or any agency thereof. 


\section{DISCLAIMER}

Portions of this document may be illegible in electronic image products. Images are produced from the best available original document. 


\begin{abstract}
Issued by Sandia National Laboratories, operated for the United States Department of Energy by Sandia Corporation.

NOTICE: This report was prepared as an account of work sponsored by an agency of the United States Government. Neither the United States Govern ment nor any agency thereof, nor any of their employees, nor any of their contractors, subcontractors, or their employees, makes any warranty, express or implied, or assumes any legal liability or responsibility for the accuracy, completeness, or usefulness of any information, apparatus, product, or process disclosed, or represents that its use would not infringe privately owned rights. Reference herein to any specific commercial product, process, or service by trade name, trademark, manufacturer, or otherwise, does not necessarily constitute or imply its endorsement, recommendation, or favorin by the United States Government, any agency thereof or any of their contractors or subcontractors. The views and opinions expressed herein do not necessarily state or reflect those of the United States Government, any agency thereof or any of their contractors or subcontractors.
\end{abstract}

Printed in the United States of America

Available from

National Technical Information Service

Royal Road

Springfield, VA 22161

NTIS price codes

Printed copy: A04

Microfiche copy: A01

LI

Lom 1

$\sum_{-\infty}^{\infty} \frac{1}{6}$

$\lim _{2} \frac{1}{1}$

0 
SAND $82-0863$

EULER BUCKLING OF GEOTHERMAL WELL CASING

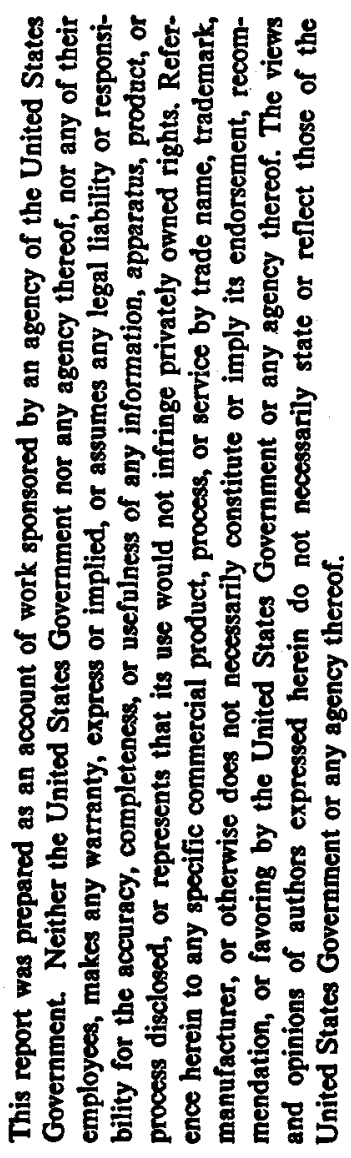

R. P. Rechard

K. W. Schuler

\begin{abstract}
Applied Mechanics Division
Sandia National Laboratories

Albuquerque, New Mexico 87185
\end{abstract}

HOTTEE

PORTIOHS OF THIS REPORT ARE ILLEIELE.

it has been reproduced from the best

avallable copy to permit the broadest

possible avallabllity.

\title{
ABSTRACT
}

Geothermal well operators have expressed concern over the vulnerability of unsupported casing to buckling from thermal elongation. In this report, we present preliminary numerical and theoretical calculations, which indicate the buckling phenomenon should not be serious in $N-80$ casing if the string is tension preloaded. Buckling would be detrimental for K-55 casing. The effect of wall contact was found to be beneficial for closely confined pipe strings and of no detriment when hole gaps are large. The weakness of API screw joints in bending appears to be the structural limitation. The analysis assumed stresses above yield constituted failure, that thermal expansion was strain controlled, and that the casing was continuous. Excessive internal pressure instability was ignored. The temperature variation considered was between cementing conditions of $100-200^{\circ} \mathrm{F}\left(40-95^{\circ} \mathrm{C}\right)$ and shut-in conditions of $425-450^{\circ} \mathrm{F}\left(220-230^{\circ} \mathrm{C}\right)$. 


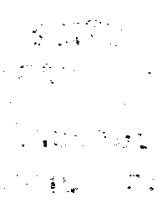

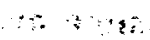




\section{CONTENTS}

Page

INTRODUCTION. • • • • • • • • • • • • • • • • • 1

Geothermal Well Construction . - . . . . - . 1

Well Casing Design. - • - . . - . . . . - 5

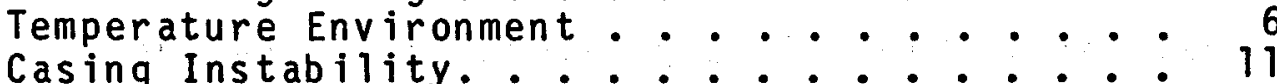

ANALYSIS. • • • • • • • • • • • • • • 17

Theoretical Model . . . . . . . . . 17

Numerical Model ............... . . 30

Addition of Constant Stress . . . . . . 33

Analytic Summary. . . . . . . . . . . . 33

RESULT IMPLICATIONS • . . . . . . . . . . 35

Thermally Induced Euler Buckling. . . . . . 35

Joint Behavior... . . . . . . . . . . . 37

SUMMARY AND CONCLUSIONS • . . • . . . . . . . 39

REFERENCES. - . . . . . . . . . . . . . . . 41

APPENDIX A - Nomenclature . . . . . . . 43

APPENDIX B - Derivation of Equations. . . • • 45 


\section{ILLUSTRATIONS}

Figure

1. Typical Geothermal Well Construction and

Casing Temperature Profile. . . . . . . . . 3

2. Idealized Conditions Causing Casing Buckling

with Temperature Excursion........... 7

3. Preliminary GEOTEMP Calculations of

Temperature Conditions During Cementing . . . . 9

4. Postulated Buckling Failure Modes: a) Local,

Plastic Deformation, b) Euler buckling,

c) Euler Buckling with Subsequent Wall Contact, and d) Helical Buckling . . . . . . . . . . 12

5. Qualitative Plot of Temperature Charige Versus

Unsupported Length Depicting Buckling Regions • 14

6. Definition of Terms: a) Line Sketch and

b) Free Body Diagram. . . . . . . . . . . . 19

7. Locus Delineating Euler Buckling Region: Plot

of Temperature Change $(\Delta T)$ Versus Normalized

Unsupported Length $(L / D)$. . . . . . . . . . . 21

8. Maximum Stress ( $\sigma$ ) Versus Temperature Change

( $\Delta T$ ) for 13-3/8 inch 54.5 ppf Casing Assuming Unsupported Lengths (L/D) of 50, 100, and 200 . 25

9. Maximum Deflection Versus Temperature Change

$(\Delta T)$ for 13-3/8 inch 54.5 ppf Casing Assuming Unsupported Lengths ( $L / D)$ of 50,100 , and 200 . 26

10. Deformed Casing Shapes with Wall Constraint Predicted by MARC and Theoretical Models at

a) $\Delta T=80^{\circ} \mathrm{F}$, b) MARC Results at $\Delta T=300^{\circ} \mathrm{F}$, and c) Analytic Results at $\Delta T=300^{\circ} \mathrm{F} . . . .$.

11. Maximum Stress (o) Versus $\Delta T$ for 13-3/8 inch 54.5 ppf Casing for Unsupported Length (L/D) of 100 with Wall Contact: a) Analytic Model, b) MARC Computer Code, and c) Constant Stress Addition.................. 29 


\section{INTRODUCTION}

Drilling for geothermal energy began as early as the 1920's in the Geysers field in northern California, but a serious effort to harness geothermal energy for power generation was not begun in the United States until the 1970's, On a national scale, there is the geologic potential to develop 20,000 MW of electrical energy. The geothermal energy industry performance in the 1 ast 10 years and the geologic prospects indicate the industry has the potential for growth and can make a contribution in supplying the energy needs of the nation.

There are numerous similarities between conventional oil and gas wells and geothermal wells in construction and operation. However, important differences do exist (whether from dry steam, dry hot rock, hot water, or geopressurized fluid reservoirs). Fluid flow rates are an order of magnitude larger than in the petroleum industry. The high temperatures encountered affect the drill bit, drilling mud and the cement performance. Reservoir calculations must include an energy balance as well as a mass balance. Finally, diffjcult geology, corrosive environments, and thermal stresses induced in the well casing present the casing designer with a new set of failure modes to consider.

Geothermal Well Construction

This introduction is intended to provide the reader unfamiliar with geothermal well casing design and construction necessary background information. However, it also serves to remind the reader that although the casing selection is based on the worst case design criteria from burst, collapse, tension, etc., stresses from many different loads can be 
present simultaneously and contribute to casing failure. More comprehensive discussions of the various facts of Geothermal wells are available (e.g. Edwards et al., 1982).

Figure 1 shows a schematic of a geothermal well which will be used for discussion. Temperature profiles of the casing and undisturbed formation are also shown. Figure 1 contains well features from several types of geothermal fields and thus cannot truly be classified as "typical."

The well is shown vertical, but frequently geothermal wells are directionally drilled. Appropriate drill sites are difficult to locate in the rough terrain often found above geothermal fields. It is also desirable to drill at an angle to intersect more fractures. Geothermal reservoirs frequently occur in fractured reservoirs below $3000 \mathrm{ft}(900 \mathrm{~m})$; hence fractures are primarily vertical.

Most geothermal reservoirs are below the drill mud hydrostatic pressure which causes lost circulation problems during drilling and cementing. Also, low geothermal reservoir pressures make detection of steam or hot water bearing fractures difficult. The use of air reduces the drill fluid density and greatly speeds up drilling. However, the drill bit life is greatly reduced because of the high temperatures encountered. The near sonic velocities produced while carrying the cuttings up the outside of the drill pipe also causes excessive erosion of the drill pipe.

The standard components of the well casing program are conductor pipe, surface casing, intermediate casing and production casing. The production casing is often set as a production liner with a tieback. Production casing and production liners are designed with the same criterion as intermediate casing and drilling liners except that consideration of drilling wear is not required. The well construction differs slightly from conventional oil wells in that each casing is cemented to the surface.

Conductor pipe is the first string of pipe to be installed. It aids in preventing washouts around the drill 


\section{GEOTHERMAL WELL SCHEMATIC \\ AND CASING TEMPERATURE}

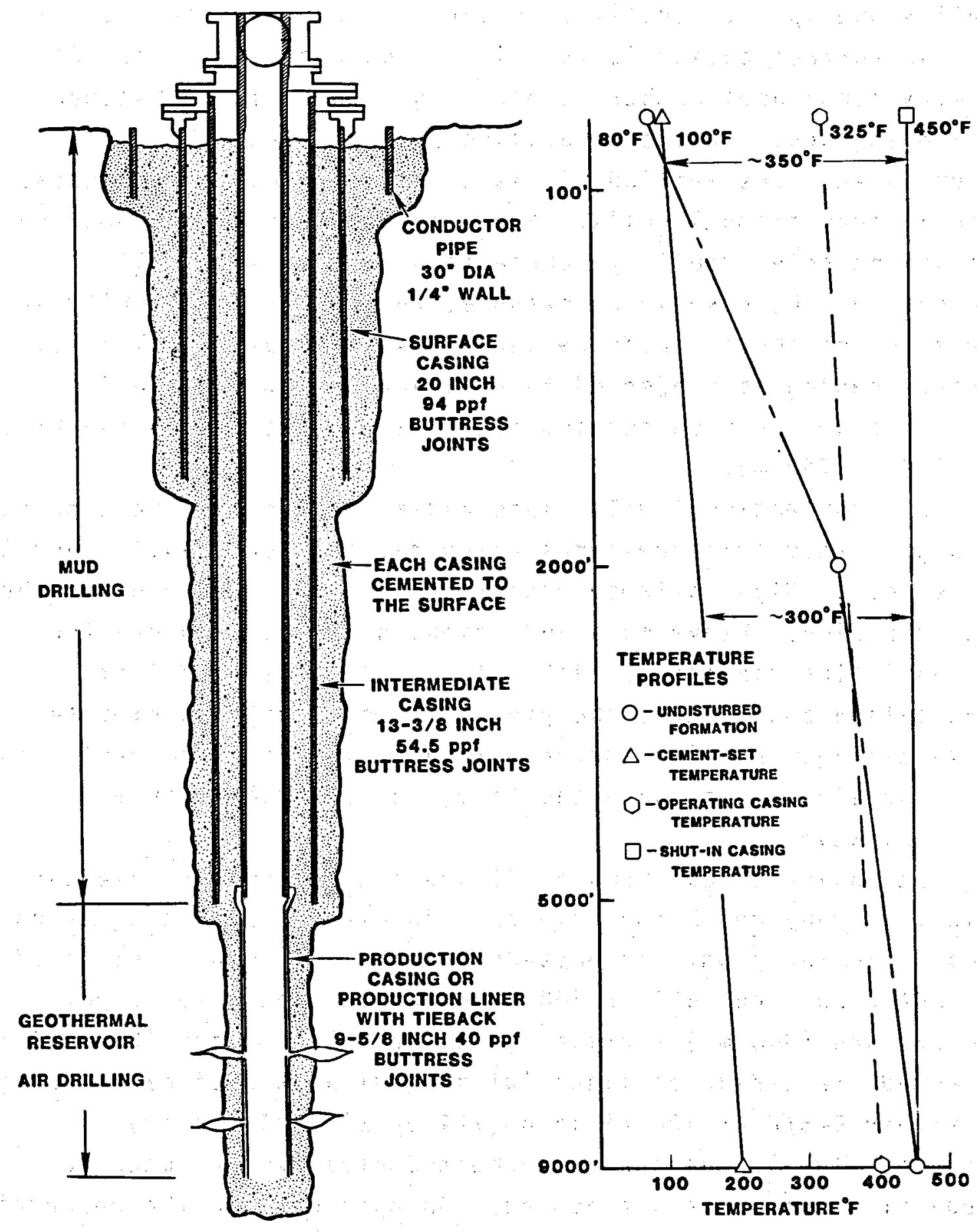

Figure 1. Typical Geothermal Well Construction and Casing 
rigs, provides a conduit for drilling fluids to surface pits, and helps support well head equipment. Conductor pipe is set shallow and is not usually considered a pressure string.

The surface casing is the first true casing string. As a primary structural member it provides support for subsequent casing strings. To avoid buckling problems from the compressive loads applied, it is often cemented to the surface even in conventional wells. Surface casing must also provide sufficient hole stability, protection to aquifers, solid support for the reservoir pressure, and pressure integrity in the event of abrupt pressure increases (blowouts and kicks). Surface casing is subjected to drilling wear which requires heavy casing. Common setting depths are between 1000 and 2500 ft $(300$ to $760 \mathrm{~m})$.

In a conventional well, intermediate casing can be exposed to high bottom hole pressures which requires substantial burst resistance. High collapse resistance is also required for the deeper casing. Heavy muds and cement slurries required for deep drilling can create high collapse loads should lost circulation zones empty the pipe. These conditions dictate heavy casing. As with surface strings, intermediate casing and drilling liners are subjected to mechanical damage from drilling wear.

The casing sizes shown in Figure 1 are commonly selected values in many geothermal fields. However, a standard casing program in the prominent Geysers geothermal field consists of 26 and/or 20 inch (660 or $508 \mathrm{~mm}$ ) diameter conductor pipe, $13-3 / 8$ inch $(340 \mathrm{~mm}$ ). surface casing, and $9-5 / 8$ inch (244 mm) intermediate casing or liner (with or without a tieback string of either $9-5 / 8$ or $10-3 / 4$ inch (244 or $273 \mathrm{~mm}$ ) casing) (Capuano, 1979). Because superheated steam is produced, a production casing is not needed. An open hole in the reservoir is usually stable. 
We11 Casing Design

The proper selection of the type, size, and setting depth of the well casing is based on the expected well operation conditions and the drilling site geology. The usual practice is to consider the worst case or maximum load in determining the required casing configuration. Complications due to casing nesting are usually ignored. A list of casing failure modes includes (Snyder, 1979):

- Metal failure: burst, collapse, tension, or corrosion,

- Mechanical damage: drill pipe wear, welding problems, threat damage, or leakage and perforation,

- Casing instability: lateral deflection (buckling) from excessive compressive loads (e.g thermal expansion) or internal pressure,

- Cement failures: voids from lost circulation zones or cement tool problems, cement dissolution and corrosion permitting fluid movement between casing and formation, or poor high-temperature slurry behavior,

- Thermal stress failures: compression and/or tension failures (telescoping), leakage in couplings from cyclic loading, excessive bending loads in dog legs, strain beyond ultimate.

This tabulation presents possible failure modes. Unfortunately little detailed public information exists on geothermal well casing failures. The analyst can only postulate types and failure mechanisms and thus the danger exists that an important or more likely failure mechanism has been overlooked.

It should be noted that the failure modes listed are not independent. For example, a cement failure could cause insufficient lateral support and result in casing instability when high internal pressures occurred. The resulting lateral deflection could in turn result in excessive drill pipe wear during the drilling operation and subsequent burst of the casing during the production operation. 
In oil or gas well casing design, the major concern addressed is metal failure from burst, collapse, or tension. However, the presence of thermal loads in geothermal well casing greatly increases the opportunity for casing instability. Casing stability can be improved by:

1) cementing the entire string to provide lateral support or 2) applying a tension load in the uncemented sections. Fully cementing the casing string is the usual choice. Unfortunately, poor formation conditions frequently exist in geothermal areas. The reservoir is usually below hydrostatic pressure and can be highly fractured. Consequently, lost circulation while drilling with mud or cementing casing is common. It is thus impossible to ensure a complete cement job in many instances. Failure of stage cementing tools in geothermal wells is frequent and also creates unsupported tubular sections (Snyder, 1979). Buckling failures of the casing from thermal expansion where cement failures have occurred is the subject of this report (Figure 2 ).

Temperature Environment

The temperature environment is important information for the thermal analysis. Figure 1 presents a hypothetical temperature environment. The surface and bottom hole temperatures are as surmised by the well operators in The Geysers field (Pye, 1980; Jenkins and Snyder, 1979), but the actual temperature profiles throughout the stratigraphy and casing are unknown. In Figure 1 casing temperatures are assumed to vary linearly. The undisturbed formation profile is shown with one elbow. A few profiles available from The Geysers field contain two kinks: the second elbow occurs with in the first $500 \mathrm{ft}(150 \mathrm{~m})$.

For wells completed in low-pressure hot-water or steam reservoirs, the casings are thought to be cemented at a temperature between $100-200^{\circ} \mathrm{F}\left(40-95^{\circ} \mathrm{C}\right)$. This assumes the 


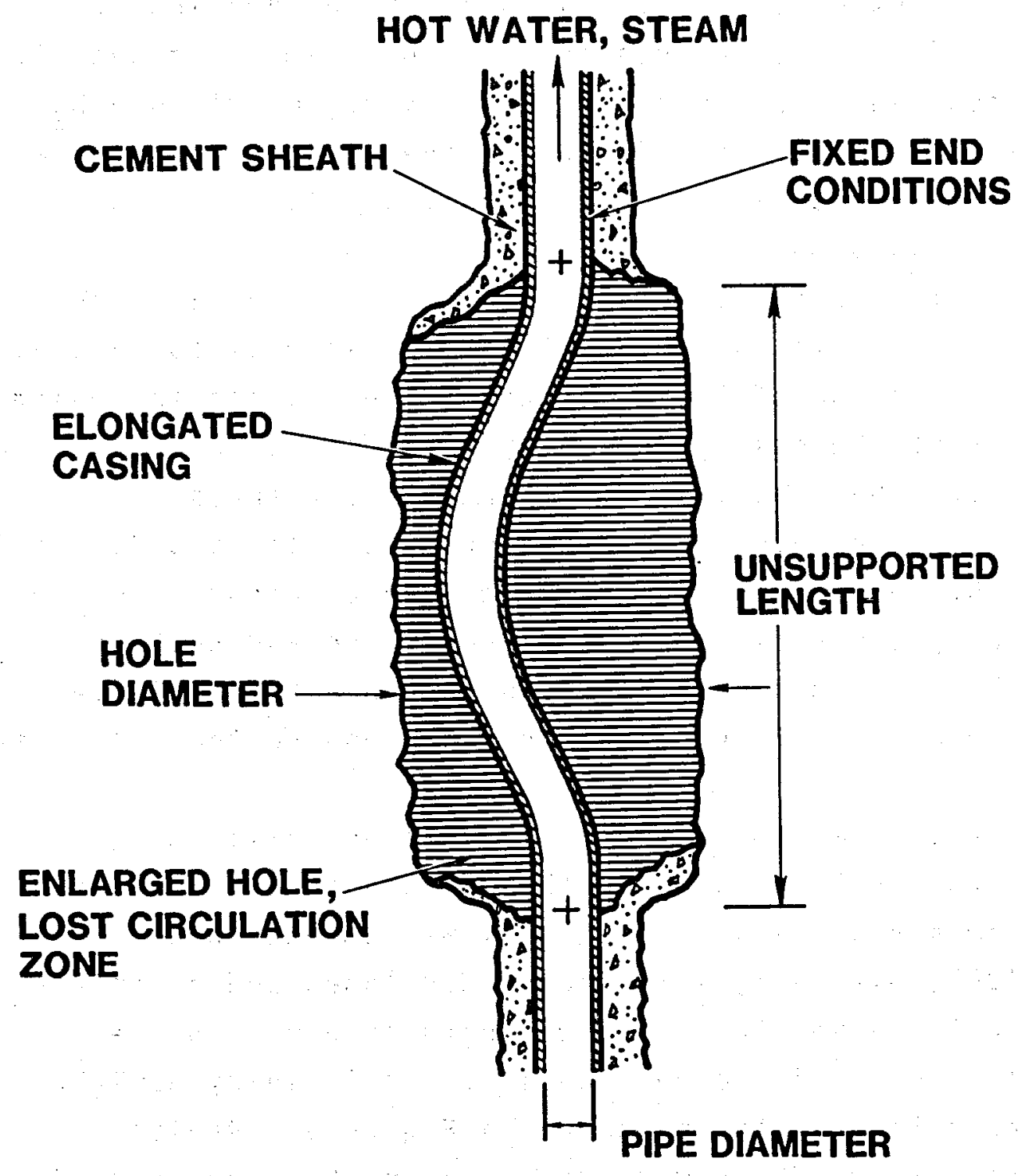

Figure 2. Idealized Conditions Causing Casing Buckling with Temperature Excursion. 
casing is not purposely allowed to heat up before cementing. Upon completion, the well is temperature cycled between producing conditions of approximately $325-400^{\circ} \mathrm{F}\left(160-205^{\circ} \mathrm{C}\right)$ and shut in conditions of $425-450^{\circ} \mathrm{F}\left(220-235^{\circ} \mathrm{C}\right)$. The cycling is due to air pollution standards which limit the venting of geothermal wells. Cycling can occur 2 to 3 times per week if the steam contains a pollutant such as hydrogen sulfide $\left(\mathrm{H}_{2} \mathrm{~S}\right)$. When the well requires remedial work, the casing temperature is reduced to around $100^{\circ} \mathrm{F}\left(40^{\circ} \mathrm{C}\right)$ with cool water. These are approximate values only.

A temperature profile is very useful in visualizing the temperature change to which each type of casing is subjected. Accurate information of this type would greatly aid the design and analysis of the casing integrity. As seen in Figure 1, the casing can be subjected to large temperature changes.

Consequently large thermal stresses must be anticipated. It is seen that the more severe temperature changes occur near the surface during the cycling between production and shut-in. However, the whole casing string can be subjected to large temperature changes after cementing and whenever the well must be quenched.

An accurate cement-set temperature is essential to the thermal stress analysis because this is the temperature the casing becomes constrained. The GEOTEMP computer program (Wooley, 1980; Mitchell, 1982) being developed under contract to Sandia will be helpful in more carefully defining the temperature regime of the well casing. Preliminary GEOTEMP temperature calculations are shown in Figure 3 . Radial temperatures at $200 \mathrm{ft}(60 \mathrm{~m})$ depth under three geothermal fluid flow conditions are depicted for a Geysers well. The cementing conditions are lower than generally assumed by operators. Verification of the GEOTEMP program is not complete, but the temperature difference shown could be significant and needs to be more carefully examined. 


\section{PROFILES TAKEN FROM GEOTEMP ANALYSIS}

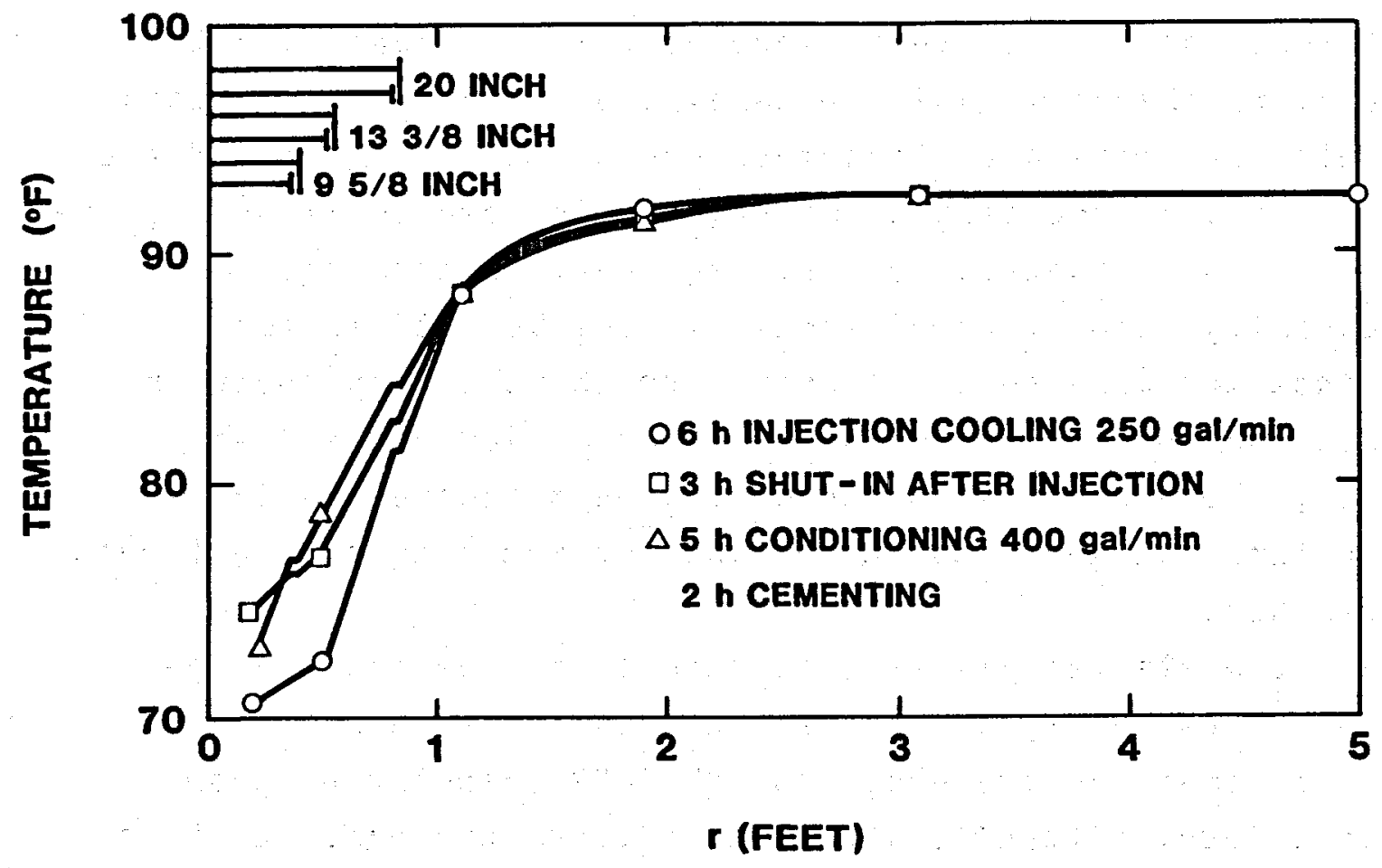

RADIAL TEMPERATURES AT 200 FOOT DEPTH

Figure 3. Preliminary GEOTEMP Calculations of Temperature Conditions During Cementing. 
casing is not purposely allowed to heat up before cementing. Upon completion, the well is temperature cycled between producing conditions of approximately $325-400^{\circ} \mathrm{F}\left(160-205^{\circ} \mathrm{C}\right)$ and shut in conditions of $425-450^{\circ} \mathrm{F}\left(220-235^{\circ} \mathrm{C}\right)$. The cycling is due to air pollution standards which limit the venting of geothermal wells. Cycling can occur 2 to 3 times per week if the steam contains a pollutant such as hydrogen sulfide $\left(\mathrm{H}_{2} \mathrm{~S}\right)$. When the well requires remedial work; the casing temperature is reduced to around $100^{\circ} \mathrm{F}\left(40^{\circ} \mathrm{C}\right)$ with cool water. These are approximate values only.

A temperature profile is very useful in visualizing the temperature change to which each type of casing is subjected. Accurate information of this type would greatly aid the design and analysis of the casing integrity. As seen in Figure 1 , the casing can be subjected to large temperature changes. Consequently large thermal stresses must be anticipated. It is seen that the more severe temperature changes occur near the surface during the cycling between production and shut-in. However, the whole casing string can be subjected to large temperature changes after cementing and whenever the well must be quenched.

An accurate cement-set temperature is essential to the thermal stress analysis because this is the temperature the casing becomes constrained. The GEOTEMP computer program (Wooley, 1980; Mitchell, 1982) being developed under contract to Sandia will be helpful in more carefully defining the temperature regime of the well casing. Preliminary GEOTEMP temperature calculations are shown in Figure 3 . Radial temperatures at $200 \mathrm{ft} .(60 \mathrm{~m})$ depth under three geothermal fluid flow conditions are depicted for a Geysers well. The cementing conditions are lower than generally assumed by operators. Verification of the GEOTEMP program is not complete, but the temperature difference shown could be significant and needs to be more carefully examined. 
While failures in cemented strings such as compression and/or tension failures and connection failures are of concern, operators have expressed greater concern over casing buckling in partially cemented strings (Pye, 1980; Kumataka, 1981, Snyder, 1979). As regards partially cemented strings, work in the arctic oil fields has shown that the cement and/or formation support needed to avoid buckling from subsidence is quite small (Wilson et al., 1980). (Both subsidence and thermal stress loads are strain controlled.). Because little lateral support is necessary, buckling is limited to areas where formation conditions cause enlarged holes to form with subsequent voids in the cement sheath such that a completely unsupported section occurs (Figure 2).

Casing instability failures from a thermal load in partially cemented strings can be divided into four categories. The failure type is dependent on the unsupported casing length and internal-external pressure interaction (Figure 4). The categories are:

- Local plastic deformation, - Euler buckling,

- Constrained Euler buckling followed by plastic deformation or collapse due to ovalation,

-Helical buckling.

It is important to emphasize the difference between standard column buckling under an applied load and casing buckling from thermal forces where support of a follower axial load is not required. Rather than catastrophic failure from a critical temperature change, the casing slowly deforms elastically into the deformed shape for large unsupported lengths. Thus column "bending" is a more appropriate description of the phenomenon. The pipe string instability manifests itself as a lateral deflection. 


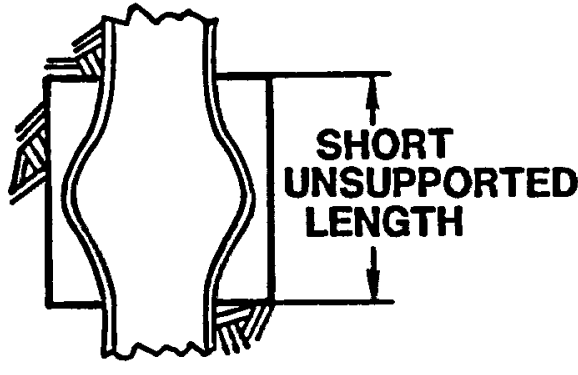

a) LOCAL, PLASTIC DEFORMATION

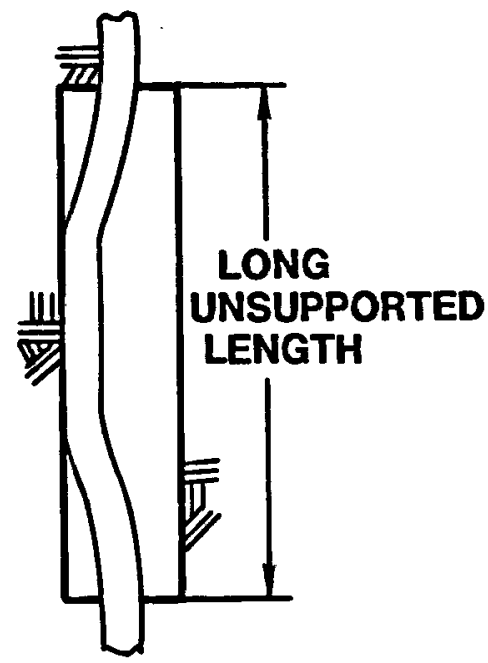

c) EULER BUCKLING WITH SUBSEQUENT WALL CONTACT (PLASTIC DEFORMATION OR COLLAPSE DUE TO OVALATION POSSIBLE)

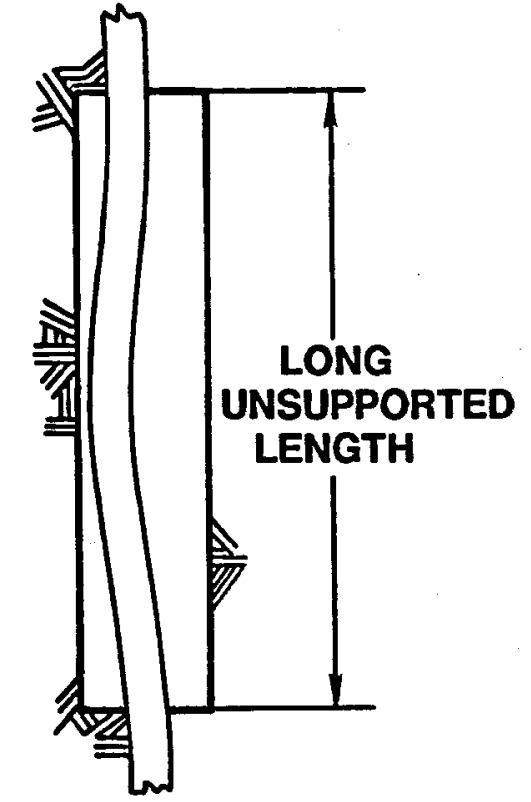

b) EULER BUCKLING

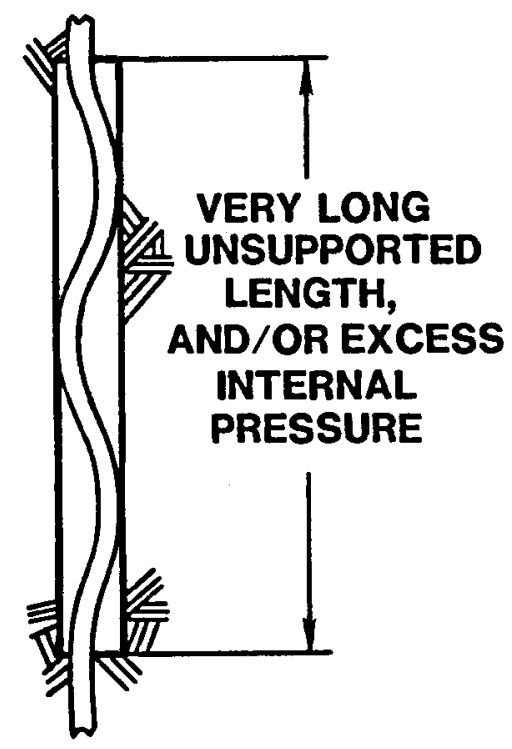

d) HELICAL BUCKLING

Figure 4 .

Postulated Buckling Failure Modes:

Plastic Deformation, b) Euler Buckling,

c) Euler Buckling with Subsequent Wall Contact, and d) Helical Buckling. 
The resulting deformation may not impede operations if the deformation is slight. The largest thermal stresses are introduced during shut-in after the well is completed, thus the danger of excessive pipe wear during drilling has passed. However, even slight bending at connections can result in joint failure because standard American Petroleum Institute (API) joints are not designed to withstand bending stresses.

Figure 5 qualitatively indicates where various buckling modes occur. It is important to note that internal-external pressure interaction has been ignored. Only unsupported length and temperature was considered.

For short unsupported lengths only localized plastic deformation and/or collapse would be expected. At longer unsupported lengths, Euler buckling would occur. With continued temperature increase, the casing could deflect enough to contact the drill hole sides. Plastic deformation or pipe collapse from the weakening effects of cross-section ovalation could follow.

Helical buckling occurs in long unsupported lengths. In the oil well industry, the corkscrewing is due primarily to excessive, destabilizing, internal pressures (Lubinski et al., 1962). Frequently, the deformation is not severe enough to cause permanent deformation (Texter, 1955). Because long unsupported lengths are much less likely and the ultimate failure mechanism is similar to that encountered with single order Euler buckling, this region is of less interest.

Two basic subject areas need to be investigated concerning thermal buckling and localized plastic deformation of geothermal casing. First, analys is of the Euler buckling regime assuming built-in ends and subsequent elastic-plastic bending needs to be examined. Analys is of nested casing behavior when constrained by cement and/or formations could also be investigated more thoroughly. Second, analys is of localized plastic deformations such as symmetrical buckling and wrinkling instabilities needs to be examined. Small scale 


\section{QUALITATIVE DESCRIPTION OF VARIOUS BUCKLING MODES}

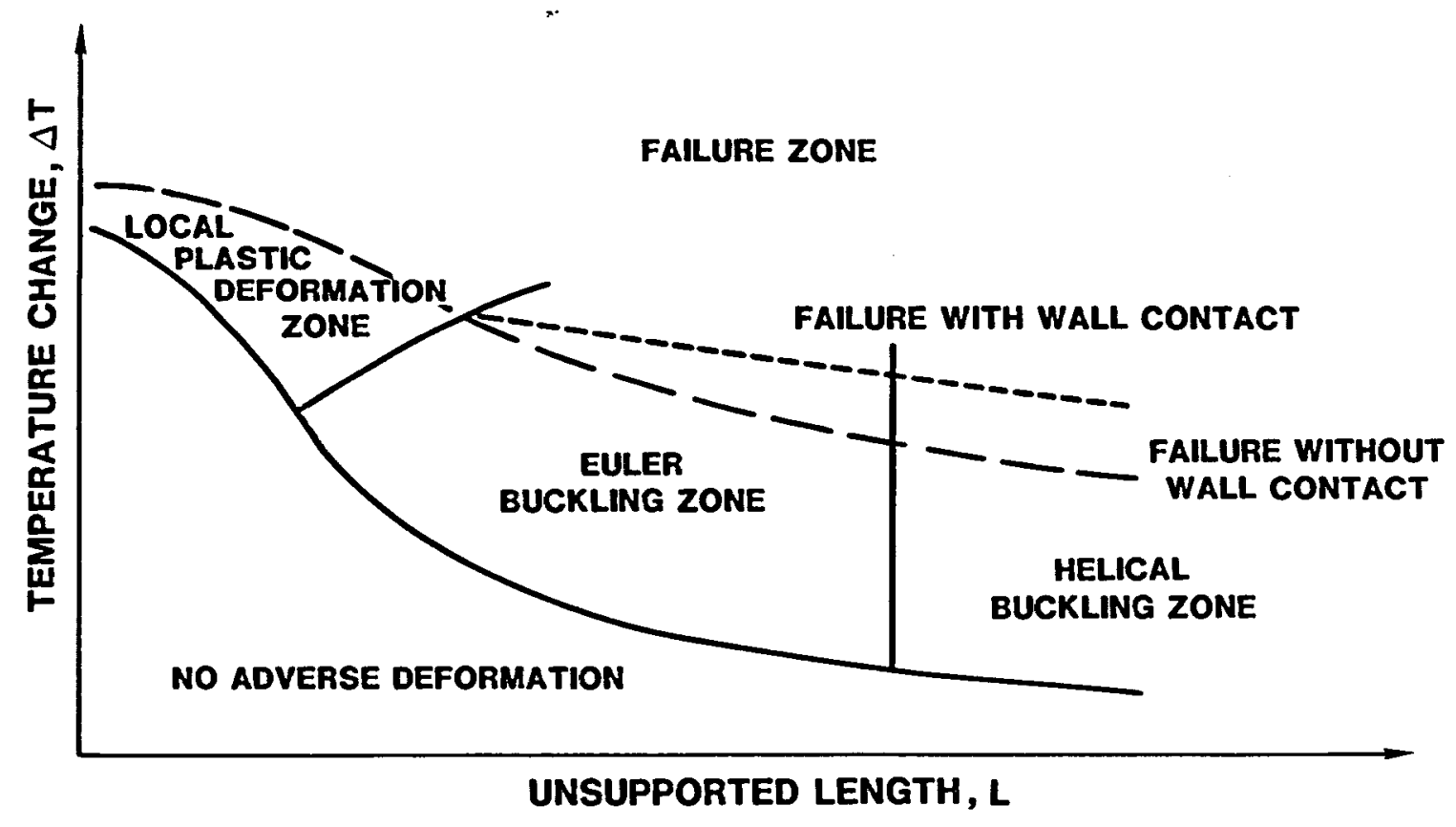

Figure 5. Qualitative Plot of Temperature Change Versus Unsupported Length Depicting Buckling Regions. 
laboratory tests of thermally-induced buckling should also be conducted to enhance the understanding of the phenomenon. This report quantitatively defines the Euler buckling regime for a casing with fixed ends with and without subsequent hole wall contact. 
16 


\section{ANALYSIS}

\section{Theoretical Model}

Assumptions. The down hole effects of improper cementing may be manifested in many ways. However, without detailed field or laboratory data on geothermal casing behavior or casing failures, there is little need to sharply focus on one subject area. Therefore a simple analytic and numerical model is presented in order to gain insight into the problem. The analysis assumed:

1) the casing was initially vertical (body forces ignored) and cementing above and below the unsupported casing provided fixed-end conditions,

2) complications from couplings such as changes in moment of inertia (I) and weakness in bending were un important,

3) casing stresses remained in the elastic region and the modulus of elasticity (E) was independent of temperature and equal to $29 \times 10^{6} \mathrm{psi}(200 \mathrm{GPa})$,

4) the linear thermal expansion coefficient (a) was constant and equal to $6.5 \times 10^{-6} \mathrm{~F}\left(1.2 \times 10^{-5^{\circ} \mathrm{C}}\right)$,

5) complications due to casing nesting were negligible,

6) the internal and external tubular pressures were equal,

7) cross-sectional shape changes (ovalation) due to lateral and bending forces were unimportant.

Assumptions 5,6 , and 7 were justified by the following facts: First, casing nesting is rarely considered in actual design applications. Second, casing ovalation problems at the wall contact were thought minor if stresses remained below yield. The nuclear reactor industry has been addressing this 
problem to some extent. Finally for low pressure, hot water, or steam reservoirs, the casing internal pressure is likely to be less than external formation pressures; hence neglecting internal-external pressure interaction was felt justified* (Lubinski et al., 1962; Hammerlind1, 1978; Jenkins and Snyder, 1979).

These assumptions permitted the application of Euler beam theory. The outline of the equation development is presented in the following section. More detailed derivations are presented in Appendix B.

Critical Temperature. A free body diagram for a deformed beam is shown in Figure 6 . The differential equation that describes the beam is as follows: (Terms are defined in Figure 6 and in Appendix A).

$$
M=M_{R}-P_{y}+V x=E I y^{\prime \prime}
$$

There are four boundary conditions:

$$
\begin{aligned}
& x=0, y=0 \\
& x=0, y^{\prime}=0 \\
& x=\ell, y=e \\
& x=\ell, y^{\prime}=0
\end{aligned}
$$

The first two boundary conditions establish the equation:

$$
y=\frac{M_{R}}{P}(1-\cos K x)+\frac{V}{P}\left(x-\frac{1}{K} \sin K x\right)
$$

where

$$
K^{2}=P / E I
$$

* As a check on this assumption, one can compare the magnitude of the thermal axial load with the load calculated from the internal-external pressure difference times the pipe cross-sectional area. The latter load should be much smaller in comparison to the thermal load. 


\section{DEFINITION OF TERMS}

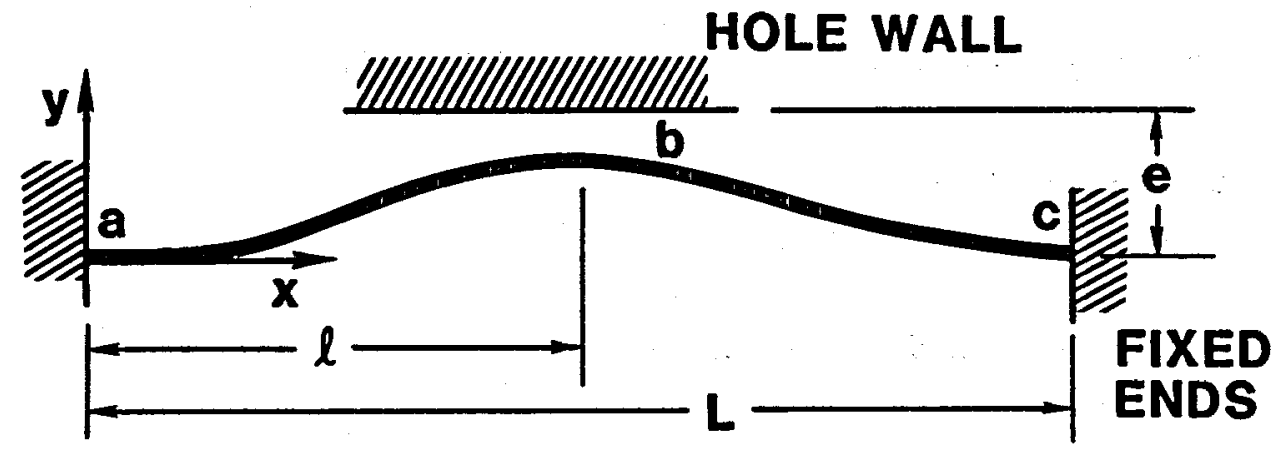

a)

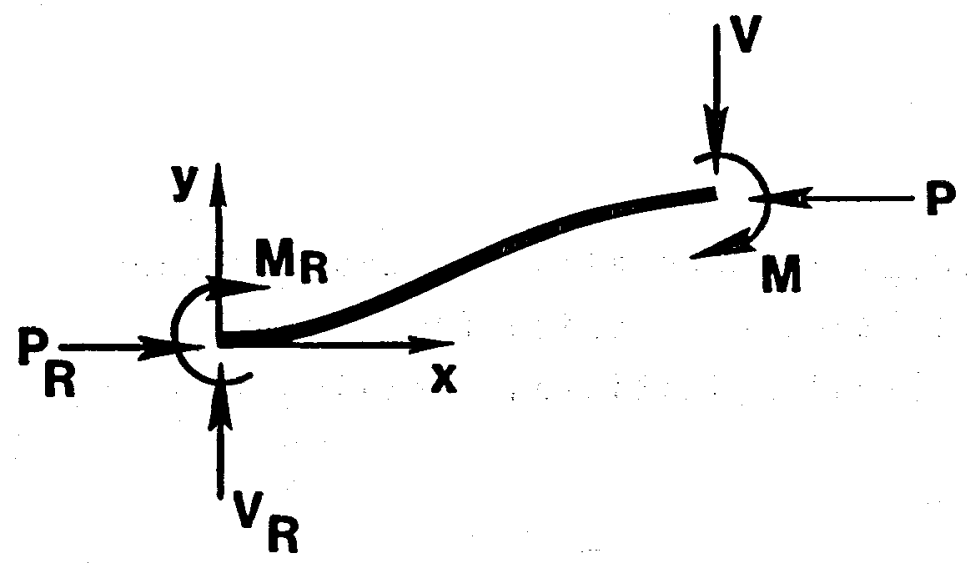

b)

Figure 6 .

Definition of Terms: a) Line Sketch and b) Full Body Diagram. 
The fourth boundary condition establishes a relationship between $M_{R}, V$, and $P$ (or $\left.K\right)$. There are three special cases as seen from the following equation:

$$
y^{\prime}=\frac{M_{R}}{P}(K \sin K \ell)-\frac{V}{P}(1-\cos K \ell)
$$

The three cases are:

1) $V=0$ and $\sin K l=0$

2) $1-\cos K \ell=0$ and $\sin K \ell=0$

3) $M_{R}=0$ and $1-\cos K \ell=0$

Case 1 is the situation before wall contact $(y<e)$. The casing takes the shape of a cosine function:

$$
y=\frac{M_{R}}{P}(1-\cos K x)
$$

where

$$
K=2 \pi / L
$$

The critical load $\left(P_{c r}\right)$ is thermally induced and thus equal to $A E \alpha \Delta T$. The resulting expression for the critical temperature change $\left(\Delta T_{c r}\right)$ which initiates buckling is:

$$
\Delta T_{c r}=\frac{4 \pi^{2} I}{L^{2} A \alpha}
$$

Figure 7 plots equation (5). The unsupported length (L) is normalized by the outside casing diameter (D). Alternately one can use the radius of gyration $\left(r_{g}\right)$ (Nelson, 1975). 


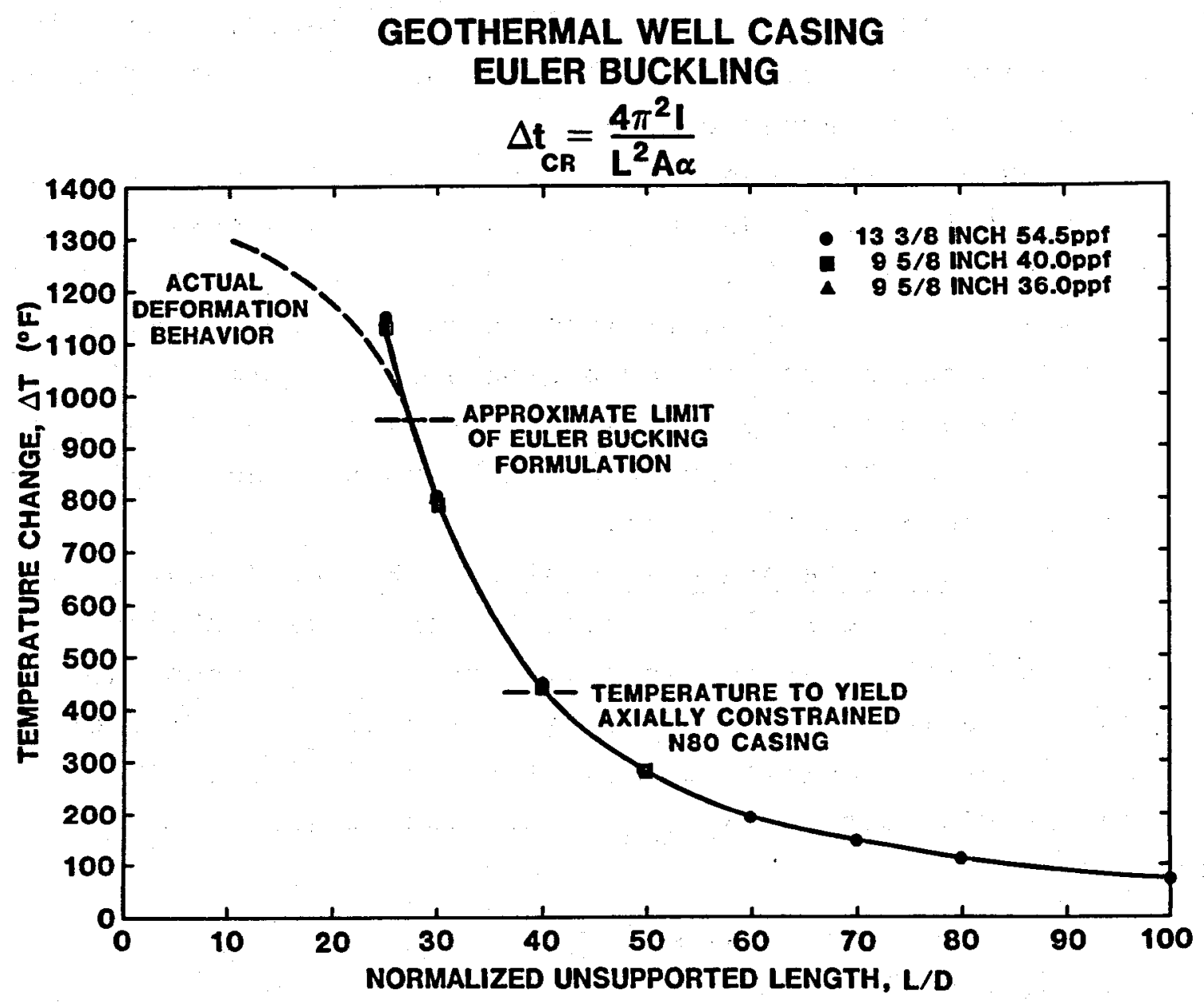

Figure 7. Locus Delineating Euler Buckling Region: Plot of Temperature Change $(\Delta T)$ Versus Normalized Unsupported Length $(L / D)$. 
Three typical casings were examined: $9-5 / 8$ inch $36 \mathrm{ppf}, 9-5 / 8$ inch $40 \mathrm{ppf}$, and $13-3 / 8$ inch $54.5 \mathrm{ppf}(244 \mathrm{~mm} 54 \mathrm{~kg} / \mathrm{m}, 244 \mathrm{~mm}$ $60 \mathrm{~kg} / \mathrm{m}$, and $340 \mathrm{~mm} 80 \mathrm{~kg} / \mathrm{m})$. Little difference between the casings exists. The moment of inertia (I) decreases slightly for the $9-5 / 8$ inch $40 \mathrm{ppf}(244 \mathrm{~mm} 60 \mathrm{~kg} / \mathrm{m})$ pipe because the outside diameter remains constant. This explains the slight decrease in $\Delta T_{c r}$ for this supposedly stronger pipe. It is important to note from equation (5) that larger diameter pipe will increase the critical buckling temperature whether or not the pipe strength increases.

The $r$ ange of applicability of equation (5) can be estimated by noting that AISC (1980) recommends the slenderness ratio $\left(K L / r_{g}\right)$ remain above $\pi\left(2 E / \alpha_{y}\right)^{1 / 2}$. This criterion was established because column failure modes such as localized plastic deformation or kinking became important for smaller values. The above criterion establishes a minimum length of $22 \mathrm{ft}(6.8 \mathrm{~m})$ or $27.5 \mathrm{D}$ for Euler buckling of $\mathrm{N}-80$ 9-5/8 inch $40 \mathrm{ppf}(244 \mathrm{~mm} 60 \mathrm{~kg} / \mathrm{m})$ casing.

Maximum stress before wall contact. Figure 7 indicates when Euler buckling will initiate. Whether the buckling results in plastic deformations must be examined from the stress standpoint. The total stress $\left(\sigma_{t}\right)$ after bending at a maximum fiber is equal to the axial stress $\left(\sigma_{a}\right)$ plus the maximum bending stress $\left(\sigma_{b}\right)_{\max }$ (ovalation stresses neglected):

$$
\sigma_{t}=\sigma_{a}+\left(\sigma_{b}\right)_{\max }
$$

where

$$
\begin{aligned}
\sigma_{a} & =P_{c r} / A=E \alpha \Delta T_{c r}=\text { constant } \\
\left(\sigma_{b}\right)_{\max } & =M_{R} r_{0} / I
\end{aligned}
$$

The end moment reaction $\left(M_{R}\right)$ in the expression for $\left(\sigma_{b}\right)_{\max }$ is found from the condition established by the fixed ends; the 
thermal displacement $(\delta(T))$ must equal the sum of the axial load displacement $(\delta(P))$ and the casing deflection displacement $(\delta(y))$ (Boley and Weiner, 1960):

$$
\delta(T)=\delta(P)+\delta(y)
$$

The displacements are expressed as:

$$
\begin{aligned}
\delta(T) & =\alpha \Delta T L \\
\delta(P) & =P_{c r} L / A E=\text { constant } \\
\delta(y) & =\frac{1}{2} \int\left(y^{\prime}\right)^{2} d x \quad \text { (Timoshenko, 1961) } \\
& =\left(\frac{M_{R} K}{2 P}\right)^{2} L
\end{aligned}
$$

Once buckling has occurred the thermally induced length change $\delta(T)$ is entirely absorbed by the column deflection term $\delta(y)$; hence, $\delta(P)$ remains constant. Consequently $\sigma_{a}$ remains at the critical buckling stress as noted above. Inserting the displacement expressions into equation (9) and solving for $M_{R}$ results in $\left(\Delta T>\Delta T_{c r}\right)$ :

$$
M_{R}=\frac{A E \alpha \Delta T_{c r}}{\pi}\left[\alpha\left(\Delta T-\Delta T_{c r}\right)\right]^{1 / 2}
$$

Assembing the expressions for $\sigma_{a}$ and $\left(\sigma_{b}\right)_{\max }$ and inserting into (6) yields:

$$
\alpha_{t}=E \alpha \Delta T_{c r}\left\{1+\frac{4 L r_{0}}{\pi\left(r_{0}^{2}+r_{i}^{2}\right)}\left[\alpha\left(\Delta T-\Delta T_{c r}\right)\right]^{1 / 2}\right\}
$$


Equation (15) is plotted for $13-3 / 8$ inch $54.5 \mathrm{ppf}(340 \mathrm{~mm}$ $80 \mathrm{~kg} / \mathrm{m}$ ) casing with $L / D=50,100,200$ in Figure 8. The upper range of applicability for Figure 8 is when the steel reaches its yield point ( $80 \mathrm{ksi}(550 \mathrm{MPa})$ for $\mathrm{N}-80 \mathrm{casing}$ ) or the casing deflects enough to contact the hole sides. The latter condition is addressed below. Figure 9 plots maximum deflection $\left(y_{\max }\right)$ versus temperature change $(\Delta T)$ and enables one to predict when wall contact would occur.

Maximum stress after wall contact. Case 2 of the boundary conditions leads to the result that $M_{R}=-M_{b}$ (Figure 6). The deformed casing shape is not compatible with these end moments. Hence case 3 , a concentrated shear load ( $V$ ) acting at the point of contact, was used to mathematically describe the casing at wall contact.* The shape of the casing between points "a" and "b" in Figure 6 is:

$$
y=\frac{V}{P}\left(x-\frac{1}{2 K} \sin 2 K x\right)
$$

Note that the end moment $\left(M_{R}\right)$ is replaced with the shear force ( $V)$. Until wall contact, the column shape is described by a cosine function (equation 2). An instantaneous change in casing shape is required. An important consequence is that stress values are not compatible when wall contact occurs using the two different shapes. Equations (4) and (16) along with computer results to be discussed later are plotted in Figure $10 \mathrm{a}$.

A solution to the predicament (subject to confirmation by numerical analysis) was to assume the column shape after contact was the same as before. The only difference was that it was "split." This assumption required imaginary end moments

* Timoshenko (1959) discusses the case of a fixed end beam uniformly loaded with foundation contact but no reference was found discussing axially-loaded members with wall contact. 


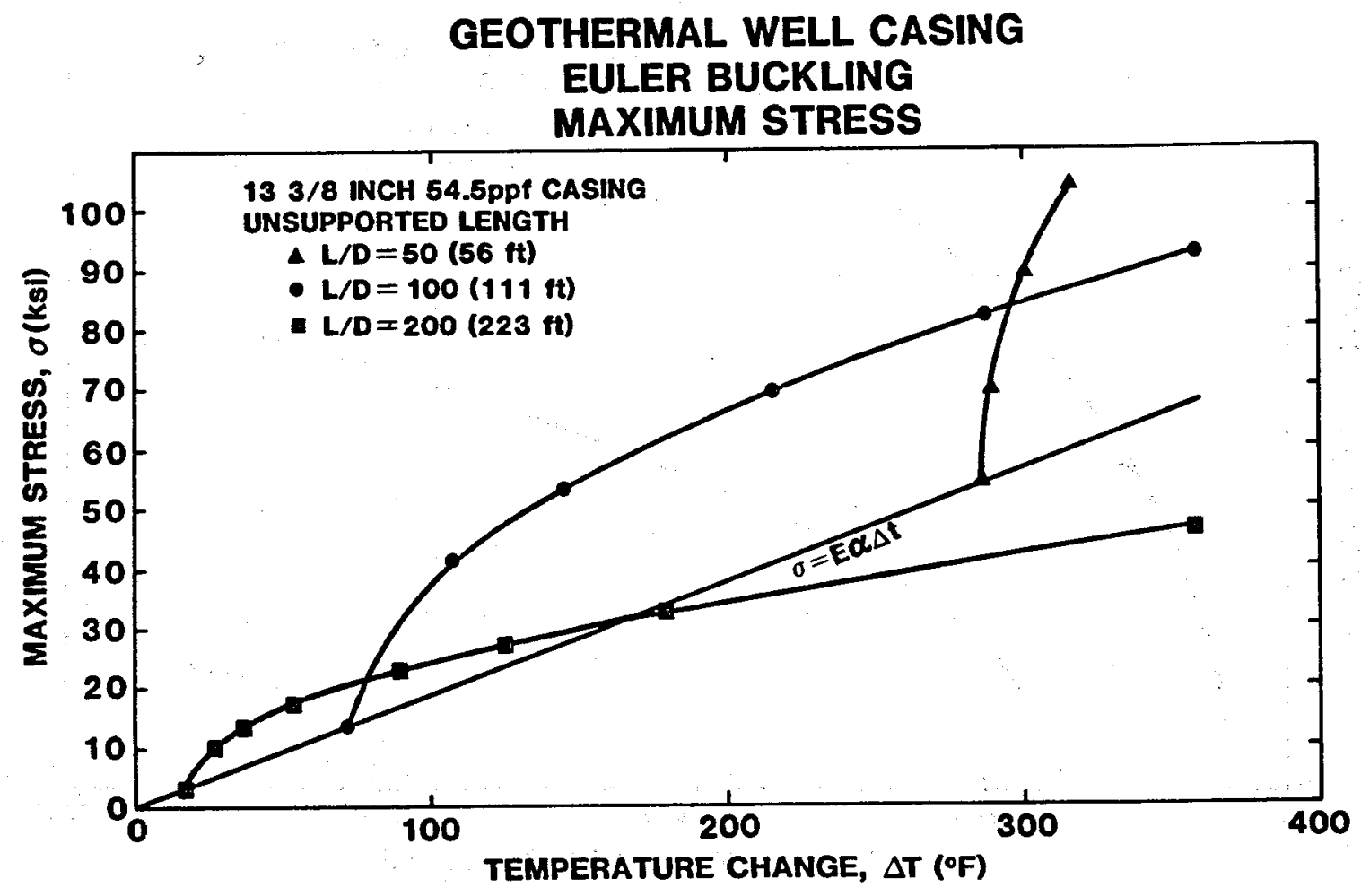

Figure 8.

Maximum Stress $(\sigma)$ Versus Temperature Change $(\Delta T)$ for 13-3/8 inch 54.5 ppf Casing Assuming Unsupported Lengths ( $L / D)$ of 50,100 , and 200 . 


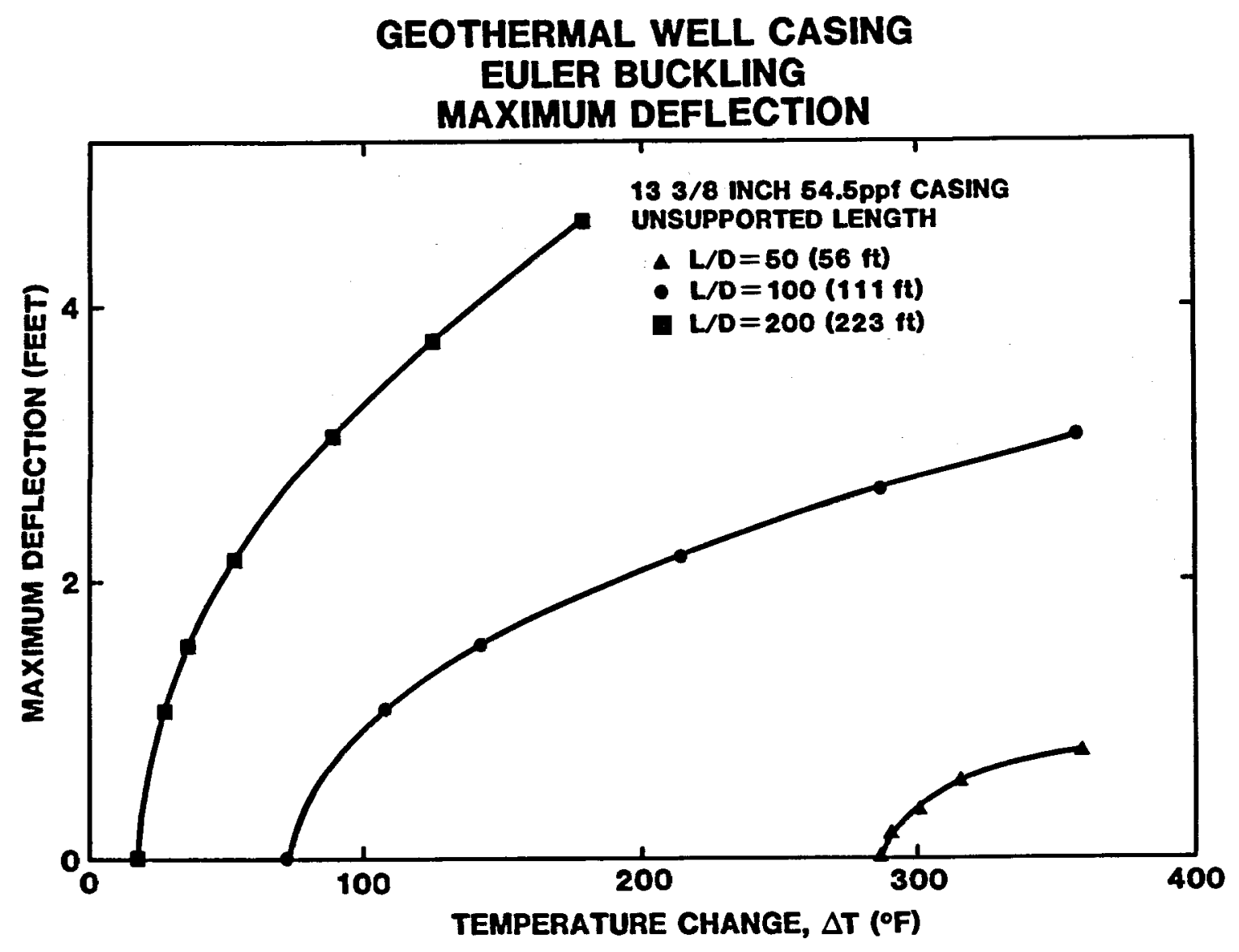

Figure 9. Maximum Deflection Versus Temperature Change ( $\Delta T$ ) for 13-3/8 inch 54.5 ppf Casing Assuming Unsupported Lengths ( $L / D)$ of 50 , 100, and 200 . 
COMPARISON OF DEFORMED

CASING SHAPES

AT $\triangle T$ EQUAL $80^{\circ} \mathrm{F}^{*}$

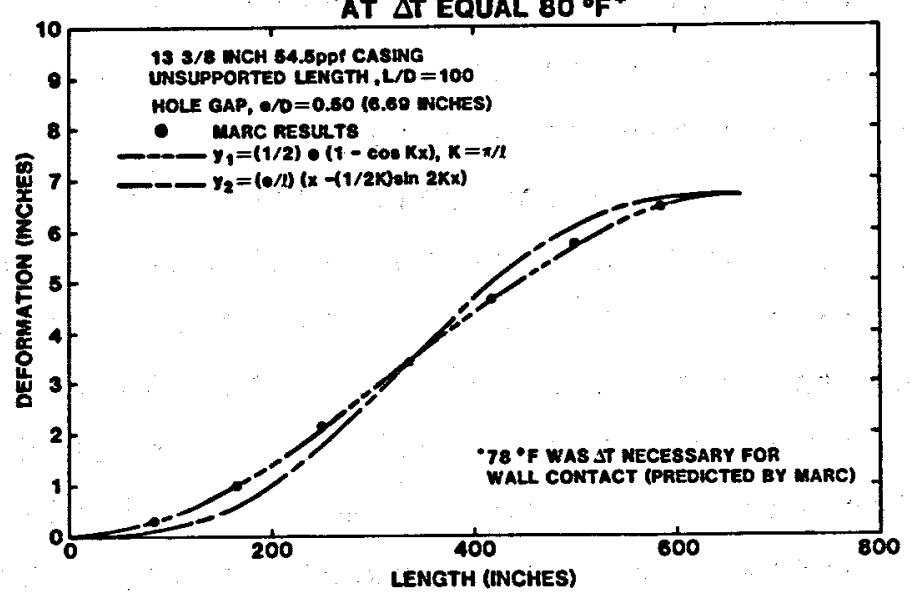

a)

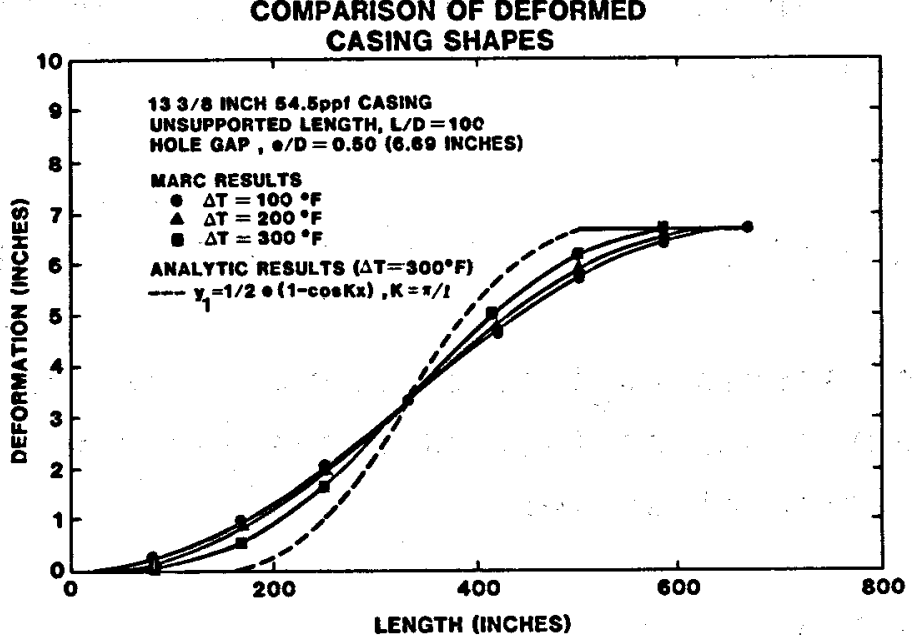

b)

COMPARISON OF DEFORMED CASING SHAPES

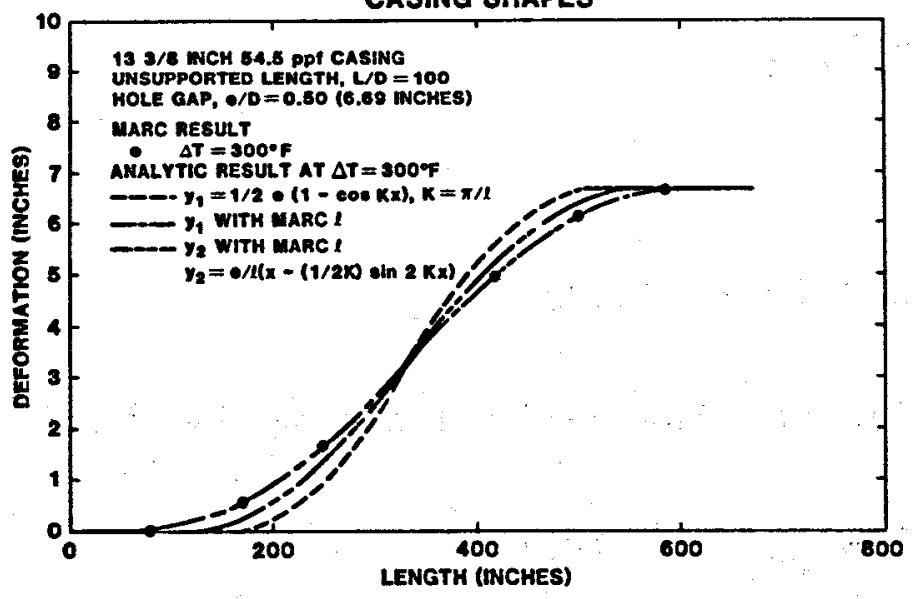

c)

Figure 10.

Deformed Casing Shapes with Wall Constraint Predicted by MARC and Theoretical Models at a) $\Delta T=80^{\circ} \mathrm{F}$, b) MARC results at $\Delta T=300^{\circ} \mathrm{F}$, and c) Analytic Results at $\Delta T=300^{\circ} \mathrm{F}$. 
$\left(M_{R}\right)$ existed equal to $P e / 2$. The mathematical model was similar to that used prior to the wall contact with the exception of a variable column length $(l)$.

Figure 6 depicts the variable length $(l)$. It is the length between the fixed end and the point of wall contact. The length ( $l$ ) shortens as the casing segment against the wall lengthens due to increased deformation. An expression for $\ell$ was found from the condition that the thermal displacement $(\delta(T)$ ) equaled the sum of the axial load displacement $(\delta(P))$ and the beam deflection displacement $(\delta(y))$. Using the same displacement expressions as before (equations (10), (11), and (12)) resulted in:

$\ell=\left\{(\pi e)^{2} A+\left[(\pi e)^{4} A^{2}+256 L^{2} \pi^{2} I A \alpha \Delta T\right]^{1 / 2}\right\} / 16 L A \alpha \Delta T$

The total stress $\left(\sigma_{b}\right)$ at a maximum fiber in the casing equals the axial stress $\left(\sigma_{a}\right)$ plus the maximum bending stress $\left(\sigma_{b}\right)_{\max }$ (equation 6 ) where:

$$
\begin{aligned}
\sigma_{a} & =E \alpha \Delta T_{c r} \\
\left(\sigma_{b}\right)_{\max } & =M_{R} r_{0} / I
\end{aligned}
$$

and

$$
M_{R}=P e / 2=\pi^{2} E I e I=\ell^{2}
$$

The expression for the maximum stress is thus:

$$
\sigma_{t}=E \alpha \Delta T_{c r}+\pi^{2} E e r_{0} / 2 \ell^{2}
$$

Figure 11 a plots equation (19) for a $13-3 / 8$ inch $54.5 \mathrm{ppf}$ $(340 \mathrm{~mm} 80 \mathrm{~kg} / \mathrm{m})$ casing 100 diameters long. Wall contact 
ANALYTIC MODEL OF

EULER BUCKLING WITH SUBSEQUENT

WALL CONTACT

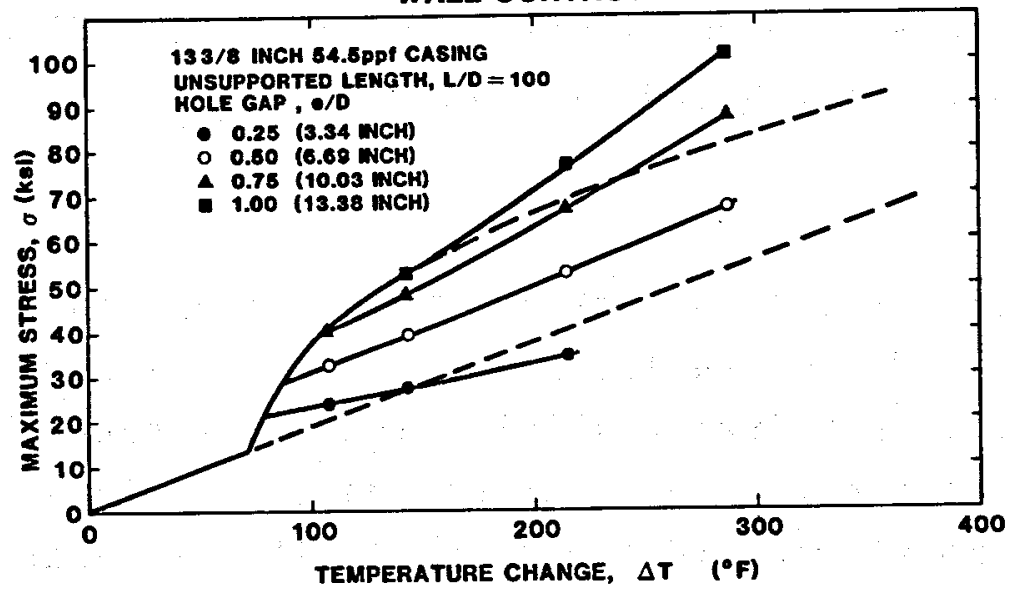

a)

MARC FE ANALYSIS USING

THIN WALLED BEAM ELEMENT

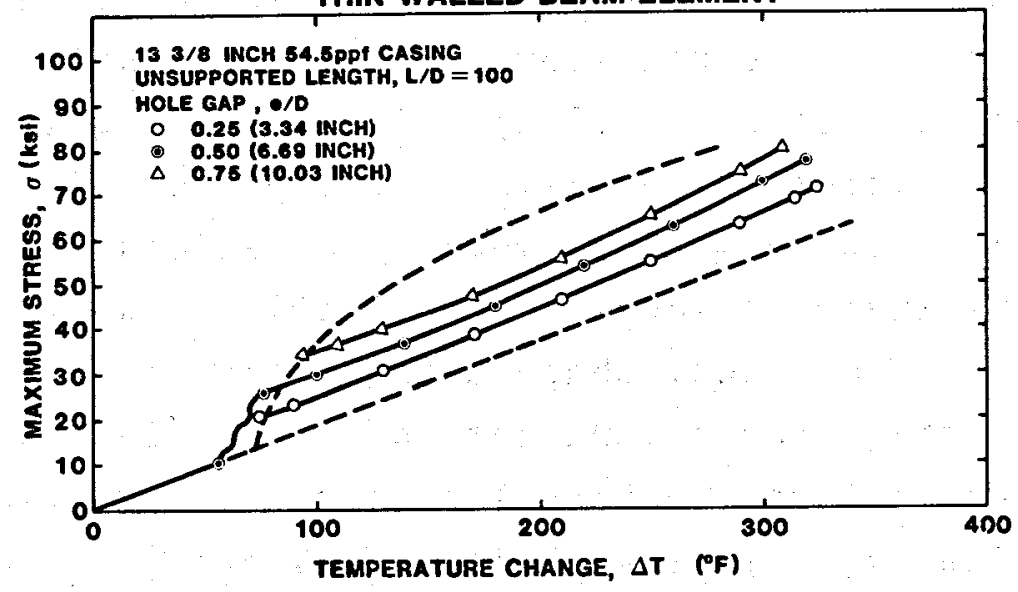

b)

\section{COMPARISON OF MARC}

ANALYSIS WITH CONSTANT STRESS CHANGE ASSUMPTION

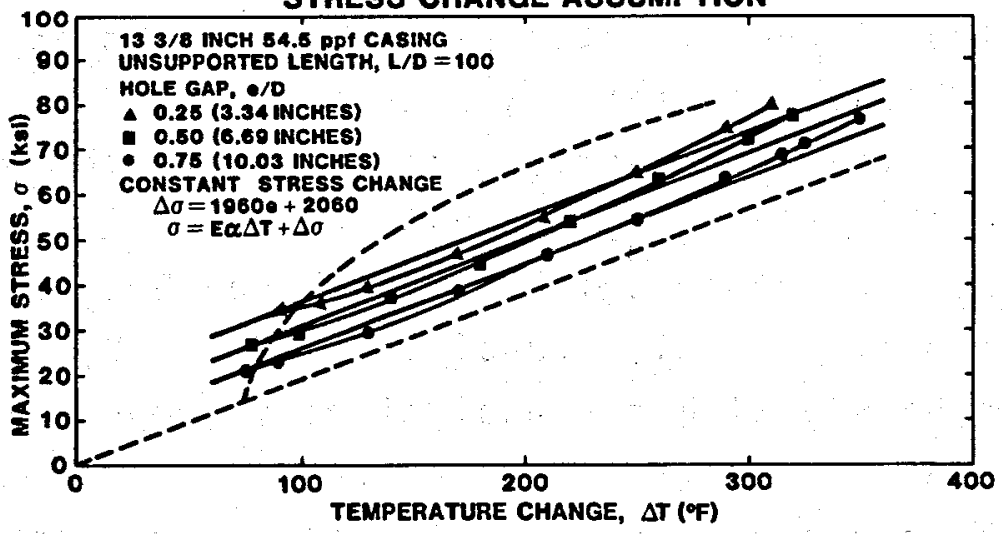

c)

Figure 11.

Maximum Stress $(0)$ Versus $\Delta T$ for $13-3 / 8$ inch $54.5 \mathrm{ppf}$ Casing for Unsupported Length (L/D) of 100 with Wall Contact: a) Analytic Mode1, b) MARC Computer Code, and c) Constant Stress Addition. (The superimposed dashed lines indicate the buckled and unbuckled stress $(E \alpha \Delta T)$ shown in Figure 8.) 
generally lowers the stress if the distance to the hole wall $(e / D)$ is less than 0.50 and temperature changes $(\Delta T)$ are within the normal $200-300^{\circ} \mathrm{F}\left(95-150^{\circ} \mathrm{C}\right) \mathrm{r}$ ange.

Numerical Model

The analysis of casing buckling is difficult for a static finite element code to handle. In addition, the numerical model formulation requires a sliding interface capability to simulate wall contact. The numerical model developed used the thin-walled beam element (Euler theory) with circular cross-section and the friction gap element from the MARC finite element program (1979). As a check, another model was also run using a standard beam-column element with an identical moment-of-inertia area ratio (I/A). The resulting stresses were practically identical until near the yield point.

Assumptions. The numerical model limitations are similar to those of the analytic model. Complications due to casing nesting and cross-sectional shape changes (ovalation) due to lateral and bending forces were not included. Casing instability from internal-external pressure interaction was neglected. Finally, only $13-3 / 8$ inch $54.5 \mathrm{ppf}(340 \mathrm{~mm} 80 \mathrm{~kg} / \mathrm{m})$ casing 100 diameters long was examined. High temperature changes were anticipated near the surface if well shutdown occurred and thus large diameter pipe was thought appropriate. The unsupported length selected was arbitrary. For this initial investigation, inelastic analys is above the yield point was omitted ( $80 \mathrm{ksi}$ ( $552 \mathrm{MPa}$ ) for $\mathrm{N}-80$ casing).

Discussion. The numerical model buckled (became numerically unstable) at $\Delta T_{c r}$ equal to $58^{\circ} \mathrm{F}\left(14^{\circ} \mathrm{C}\right)$. This value compares poorly with the analytically computed $72^{\circ} \mathrm{F}\left(22^{\circ} \mathrm{C}\right)$ critical temperature change $\left(\Delta T_{c r}\right)$. However, $\Delta T$ is a strong function of the eccentricity initially introduced in the casing model.

It was not possible to plot the entire stress path in one run. The casing would never regain stability after buckling 
even though the loading was temperature (strain) controlled; hence it was necessary to establish the casing deformation at wall contact and then proceed with the calculations. Force equilibrium occurred at $\Delta T$ equal to $78^{\circ} \mathrm{F}\left(26^{\circ} \mathrm{C}\right)$ which indicated wall contact.

Snyder (1979) claimed thermal buckling in an unsupported hole is not strain controlled. Furthermore, he hypothesized sudden horizontal movement could cause cracking of work-hardened, high grade steel. At first glance, the instability problem with MARC (1979) appears to support the sudden horizontal displacement viewpoint.

However, the rate of temperature increase would have to be very high (high strain rate) for the above hypotheses to be true. The analytic solution (Figure 8 ) suggests large horizontal movement is not possible unless casing stress has increased well beyond $\Delta T_{c r}$ before buckling. The difficulties with the MARC model may have been due to the artificial temperature increase rate, but the large computer time required to run the model precluded the use of smaller rates.

It is worth mentioning that in the Cerro Prieto geothermal field, Baja, California, the initial temperature rise to production temperatures is carefully monitored to ensure strain contro1. The procedure requires 30-60 days (Snyder, 1979). This rate would be impractical if many temperature cycles were required.

As indicated earlier, the split-cosine bell approximation (4), the theoretical curve (16), and the MARC displacement values for the deformed casing shape at the time of wall contact with a hole gap (e/D) equal to 0.50 are compared in Figure 10. Figure 10b plots the MARC deformed shapes for temperature changes $(\Delta T)$ of 100,200 , and $300^{\circ} \mathrm{F}(38,93$, and $149^{\circ} \mathrm{C}$ ) and also equation (16) at $\Delta T=300^{\circ} \mathrm{F}$. At $\Delta T$ equal to $300^{\circ} \mathrm{F}$, the difference in shape between equation (16) and MARC is great and would presumably get worse at higher temperature changes. 
For the numerical calculations, the casing contact length with the wall was quite small. At $\Delta T=300^{\circ} \mathrm{F}$ and $e / D=0.75$, MARC predicted a contact length of 10 percent of the total length using a tolerance of 0.05 inches $(1.27 \mathrm{~mm})$. This compares with 47 percent from analytic calculations.

Figure 10C shows two shape predictions at $\Delta T$ equal to $300^{\circ} \mathrm{F}$ $\left(149^{\circ} \mathrm{C}\right.$ ) developed from equation (4) and (16) using the free, unsupported length $(l)$ determined from MARC rather than analytically. The raised-cosine equation (4) coincided with the MARC data when the numerical value of $\&$ was used. Equation (16) predicted slightly more curvature.

If the numerically determined $l$ is used in the expression for stress $\left(\sigma_{b}\right)$ (equation 19), a value of $64 \mathrm{ksi}(441 \mathrm{MPa}$ ) is predicted when e/D $=0.50$ and $\Delta T=300^{\circ} \mathrm{F}\left(149^{\circ} \mathrm{C}\right)$. The maximum stress calculated numerically was $72.5 \mathrm{ksi}$ ( $500 \mathrm{MPa}$ ) (Figure 1lb). Thus, the theoretical equations provide a good shape and stress value prediction if the length $(l)$ is known.

In making comparisons between equation (4) and (16), recall that equation (4) dictates of occurs at the wall contact while equation (16) dictates $\sigma_{t}$ occurs at the quarter point of the free length. The MARC model showed $\sigma_{t}$ gradually shifting from the wall contact point at $\Delta T$ equal to $78^{\circ} \mathrm{F}\left(26^{\circ} \mathrm{C}\right)$ to the quarter point at $300^{\circ} \mathrm{F}\left(149^{\circ} \mathrm{C}\right)$ when e/D equals to 0.50 . The shift of $\sigma_{t}$ to the quarter point occurred with smaller changes in $\Delta T$ as e decreased in magnitude.

Figure llb plots $\sigma_{t}$ versus $\triangle T$ for MARC values. The analytic calculations from Figure lla are plotted for comparison. The analytic and numerical solutions compare favorably when the wall distance $(e / D)$ is 0.50 . At a hole gap

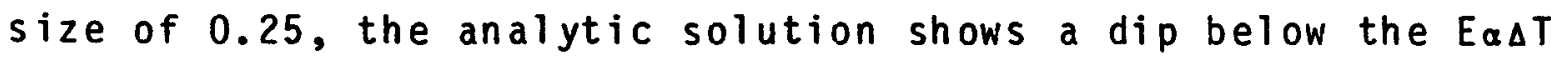
stress line. This is unrealistic and indeed the numerical solution does not cross the EasT lower limit. The numerical results indicate temperature changes up to $310^{\circ} \mathrm{F}\left(154^{\circ} \mathrm{C}\right)$ could be tolerated for e/D $=0.75$. 


\section{Addition of Constant Stress}

It is important to note the numerical results parallel the E $\alpha \Delta T$ line indicating the addition of a constant stress to the

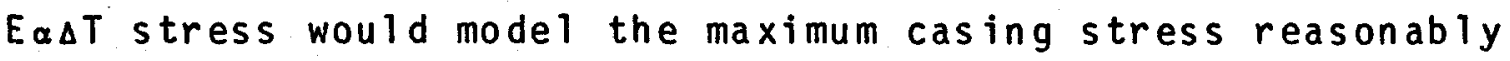
well. Assuming the stress change $(\Delta \sigma)$ is a linear function of the hole gap (e), a least squares fit results in $\left(r^{2}=0.78\right)$ (inches and psi):

$$
\begin{aligned}
\Delta \sigma & =a e+b \\
a & =1960 ; b=2060 \\
\sigma & =E \alpha \Delta T+\Delta \sigma
\end{aligned}
$$

The MARC analysis and constant stress change assumption are compared in Figure llc. Note that the simplification is valid as long as the casing contact length remains small and the hole gap (e) is small.

\section{Analysis Summary}

In summary, three predictive stress methods were examined: numerical, empirical, and theoretical. The numerical formulation for modeling the casing after wall contact was constructed using MARC beam elements. The empirical method consisted of adding a stress which was a function of the hole gap distance (e) to the thermally induced EasT stress. The equation fit the numerical results reasonably well for small e values. The theoretical model made use of simple beam theory. Buckling without wall contact was easily examined theoretically. However, the casing shape after wall contact as derived strictly from Euler beam theory was not compatible with the initial buckling phase; hence the shape and stress predictions were only in fair agreement with the numerical results. The theoretical formulation (16 and 19) provided a good shape and stress value prediction if the numerically determined wall contact length ( $l$ ) was used. 
A description of the deformed casing as a split cosine bell (equation 4 with $M_{R}=P e / 2$ ) was contrasted with the numerical results. The split-cosine formula provided a good approximation of the deformed shape. The shape description was excellent if the numerically determined wall contact length was used. The expression for the maximum casing stress was identical to that derived in the theoretical formulation. Only the expression for the length differed. 


\section{RESULT IMPLICATIONS}

Thermally Induced Euler Buckling

Looking at Figure $8, N-8013-3 / 8$ inch $54.5 \mathrm{ppf}(340 \mathrm{~mm} 80$ $\mathrm{kg} / \mathrm{m}$ ) casing with a yield stress $\left(\sigma_{y}\right)$ of about $75 \mathrm{ksi}$ (517 MPa) at $500^{\circ} \mathrm{F}\left(260^{\circ} \mathrm{C}\right)$ * and 100 diameter unsupported length would slightly exceed yield conditions if a $300^{\circ} \mathrm{F}\left(150^{\circ} \mathrm{C}\right)$ temperature excursion from cement constrained conditions of $100-200^{\circ} \mathrm{F}\left(40-95^{\circ} \mathrm{C}\right)$ occurred. These conditions roughly correspond to typical intermediate casing in geothermal wells (Figure 1). The introduction of a small tensile stress would easily reduce the stress to below yield. Consequently, simple Euler buckling should not cause a serious problem if $\Delta T$ is less than $275^{\circ} \mathrm{F}\left(135^{\circ} \mathrm{C}\right)$ for unsupported lengths $(L / D)$ above 100. Note, however, that there was no allowance for a design factor. Application of either direct tension or internal pressure during the cementing process would establish an axial tensile load although the microannulus between the casing and cement would be enlarged using internal pressure. Operators have avoided thermal well casing failures in partially cemented steam injection wells by using $\mathrm{N}-80$ or $\mathrm{P}-110$ grade casing (Holliday, 1969). This tends to confirm the low probability of problems with $\mathrm{N}-80$ casing.

The use of larger diameter pipe would increase the critical buckling temperature but not significantly. This is

* One is safe in assuming no significant reduction in ultimate casing strength occurs for temperature rises below $660^{\circ} \mathrm{F}$ $\left(350^{\circ} \mathrm{C}\right)$, but the yield strength definitely decreases with an increase in temperature. Manufacturers gener.ally do not make tensile tests at elevated temperatures and thus statistically reliable information is lacking. Karlsson (1978) suggests the use of DIN St. 45.8. The maximum possible reduction in yield strength from this formula for the above conditions is 19 percent. The above reduction of 6 percent corresponds to the minimum obtained from several private tests. 
demonstrated by Figure 7 where commonly used casing diameters plot on top of each other. In addition, the behavior after buckling might be impaired because the minimum unsupported length for Euler buckling to occur would increase.

It has been tacitiy assumed that stresses above yield constituted failure. This is a reasonable failure criterion because permanent deformation could hinder remedial work on the well. Plastic deformation was permitted at Prudhoe Bay (Goodman, 1978) where permafrost thaw produced strain controlled compressive forces, but the usually successful cement job precluded the buckling failure mode.

The casing loads along the wall contact are important as concerns casing collapse. The theoretical argument (equation $16)$ dictates an end reaction ( $V$ ) at the wall separation point. The end reaction increases with hole gap size. At $\Delta T=300^{\circ} \mathrm{F}$ and $e / 0=0.75$, an end reaction of $11900 \mathrm{lb}(52.9 \mathrm{kN})$ was calculated numerically. Using this value as a point load on a cylinder, one calculates values between 51.9 and $77.2 \mathrm{ksi}$ (358-532 MPa). The mean is slightly below the $75 \mathrm{ksi}$ (517 MPa) yield point. But the casing has definitely reached yield at the quarter point $(x / \ell=1 / 4)$. Therefore, yield is more likely to occur at the free-length quarter point first rather than at the wall contact.

Again referring to Figure 8 , the importance of buckling changes dramatically for weaker $K-55$ casing. The casing would normally yield at $\Delta T=295^{\circ} \mathrm{F}\left(145^{\circ} \mathrm{C}\right)$ with full lateral support assuming $\sigma_{y}=55 \mathrm{ksi}(380 \mathrm{MPa})$, but simple Euler buckling would produce stresses above yield with only a $155^{\circ} \mathrm{F}\left(70^{\circ} \mathrm{C}\right)$ temperature change. If a normal $200-300^{\circ} \mathrm{F}\left(95-150^{\circ} \mathrm{C}\right)$ temperature excursion occurred, the $\mathrm{K}-55$ casing would yield when buckling occurred. Lateral support would be a necessity. (The casing might.yield even with full lateral support.) The analysis has ignored the strengthening of casing nesting with complete cement jobs. This situation might warrant examination.

From Figure $11 b$ it can be generally stated that wall contact after buckling lowered casing stresses in comparison to simple 
buckling. The numerical results indicated $13-3 / 8$ inch $54.5 \mathrm{ppf}$ (340 $\mathrm{mm} 80 \mathrm{~kg} / \mathrm{m}$ ) $\mathrm{N}-80$ casing with unsupported lengths ( $L / D$ ) above 100 with gaps (e/D) below 0.75 should not experience difficulties if temperature excursions are within the normal $200-300^{\circ} \mathrm{F}\left(95-150^{\circ} \mathrm{C}\right) \mathrm{r}$ ange. These results are supported by the field evidence that production tubing, which is closely confined, seldom permanently deforms when buckled (Texter, 1955).

Lost circulation zones could potentially involve enlarged holes exceeding $e / 0>0.75$. The trend of the maximum stress $\left(\sigma_{t}\right)$ in Figure lib suggest that little detriment would occur at wall contact with greatly enlarged holes. The casing would already be near yield for the temperature change $(\Delta T)$ necessary for the large horizontal displacements.

Joint Behavior

For $N-80$ casing, a relatively high allowable $\Delta T$ was possible before the casing steel yielded. The worst case occurred during well shut-in required because of air pollution standards. If no equipment must pass through the casing during this period, the tubular material should perform satisfactorily. However, API joints are not designed to withstand bending stresses and will fracture near the last engaged thread (Greenip, 1978). Buttress thread connections match the pipe body tensile strength and are capable of withstanding between 2.3 and 3.4 percent strain (depending on whether in compression or tension) (Wooley et al., 1977), but they are still weak in bending. Consequently, joint behavior under loading could possibly be the largest factor in casing failures from buckling. Behavior of shoulder-type joints under bending should be examined to see if adequate improvements are obtained. A 100 percent joint such as the easily analyzed, fabricated, and assembled tape joint developed at Sandia may be useful. (Huerta and Black, 1976; Rechard et a1., 1982) 
38 


\section{SUMMARY AND CONCLUSIONS}

Little information is available on geothermal well casing behavior or failures; thus efforts should be made to obtain detailed description of field behavior and the criteria on which failure is based. Operators have expressed concern over casing instability as a possible failure mechanism. If a casing string is placed in axial compression from thermal elongation and if there are sizable sections where no lateral support is provided due to inadequate cement or washout zones, the string can laterally deflect (buckle).

This report provides preliminary calculations on the buckling phenomenon. It can generally be stated that thermally induced buckling in $\mathrm{N}-80$ casing would not be serious if minor adjustments to increase casing stability were made such as applying a tension preload or additional internal pressure while cementing. However, the situation is far worse for the weaker K-55 casing. Full lateral support would be a necessity.

The effect of wall contact was found to be beneficial for closely confined pipe strings and of no great detriment when hole gaps were large provided pipe ovalation was unimportant. The weakness of all American Petroleum Institute (API) screw joints in bending appears to be the structural limitation.

The above conclusions are based on the assumption that stresses above yield constituted failure. It was also assumed the thermal expansion was slow enough to produce strain controlled loads and that the casing string could be considered continuous. Internal pressure instability was ignored. The temperature variation considered was between cementing conditions of $100-200^{\circ} \mathrm{F}\left(40-95^{\circ} \mathrm{C}\right)$ and shut-in conditions of $425-450^{\circ} \mathrm{F}\left(220-230^{\circ} \mathrm{C}\right)$.

Another regime of thermal buckling which needs to be investigated is symmetrical buckling and wrinkling instabilities 
in short, unsupported casing lengths. Furthermore, it would be beneficial if laboratory experiments were conducted to: 1) observe the abruptness and extent of horizontal displacement at buckling, 2) evaluate stress reduction in the casing following wall contact, 3) evaluate weakening effects of pipe ovalness, and 4) determine the likelihood of other failure modes. 


\section{REFERENCES}

1. Manual of Steel Construction, 8th Edition, 1980, American Institute of Steel Construction, New York.

2. Boley, B. A. and J. H. Weiner, 1960, Theory of Thermal Stresses, John Wiley and Sons, Inc., New York.

3. Capuano, L. E., 1978, "How Geysers Steam Wells Are Drilled and Equipped," World 0i1, February 1, pp. 69-72.

4. Crandall, S. H., and N. C. Dah1, 1959, An Introduction to Mechanics of Solids, McGraw-Hili Book Co., Inc., New York.

5. Edwards, L. M., Chilingar, G. V., Rieke III, H. H., and Fertl, W. H., eds. 1982, Handbook of Geothermal Energy, Gulf Publishing Company, Houston.

6. Goodman, M. A., 1978, "World 0il's Handbook of Arctic Well Completions," World 0il, Houston, Texas.

7. Greenip, J. T., 1978, "Optimum Casing Program Design Stresses Economy," The 011 and Gas Journal, October 16, pp. $76-86$.

8. Hammerlind1, D. J., 1978, "Basic Fluid and Pressure Forces on $0 i 1$ Well Tubular.s," 53rd Annual Technical Conference and Exhibition of Society of Petroleum Engineers of AIME, SPE 7594, October 1-3.

9. Holliday, G. H., 1969, "Calculation of Allowable Maximum Casing Temperatures to Prevent Tension Failures in Thermal Wells," Paper 69-Pet-10, ASME Petroleum Mechanical Engineering Conference, Tulsa, OK, September 21-25.

10. Huerta, M. and J. T. Black, 1976, "Experimental and Analytical Investigation of an Interlocking Tape Joint," SAND 76-0166, Sandia National Laboratories, Albuquerque, New Mexico, October.

11. Jenkins, C. J., and R. E. Snyder, 1979, "Geothermal Well Casing Design: Basic Design Considerations," Report to Sandia National Laboratories by Completion Technology Company, August.

12. Karlsson, Thorbjorn, 1978, "Casing Design for High Temperature Geothermal Wells," Geothermal Resources Council, Transactions, Vo1.2, pp. 355-358. 
13. Kumataka, M. K., 1981, letter to James R. Kelsey, Sandia National Laboratories, from Aminoil USA, July 28.

14. Lubinski, A., W. J. Althouse, J. L. Logan, 1962, "Helical Buckling of Tubing Sealing in Packers," J. of Petroleum Technology, pp. 655-670.

15. MARC General Purpose Finite Element Program, 1979, MARC Analys is Research Corp., Palo Alto, California 94306.

16. Nelson, C. G., 1975, "Program is Designed to Analyze Casing Buckling in Thermal Recovery," The $0 i l$ and Gas Journal, December 8, pp. 79-82.

17. Mitchell, R. F., 1982, "Advanced Well Bore Temperature Simulator, GEOTEMP2, "SAND82-7003, Sandia National Laboratories, Albuquerque, New Mexico.

18. Pye, S., 1980, letter to S. G. Varnado, Sandia National Laboratories, from Union 0 il, March 15.

19. Rechard, R. P., J. T. Black and S. D. Meyer, 1982, "Guidelines for Designing Tape Joints," SAND82-2416, Sandia National Laboratories, Albuquerque, New Mexico

20. Snyder, R. E., 1979, "Geothermal Well Casing Design: A Study of Failure Modes and Cementing Limitations, "Report to Sandia National Laboratories by Completion Technology Company, May.

21. Texter, H. G., 1955, "Why 0i1-Well Tubing and Casing Fail... by Wear, Erosion, Buckling, Torsion and Corrosion," The $0 i 1$ and Gas Journal, August 29, pp. 85-99.

22. Timoshenko, S., 1959, Strength of Materials, D. Van Nostrand Co., Inc., Princeton, New Jersey.

23. Timoshenko, S., J. M. Gere, 1961, Theory of Elastic Stability, McGraw-Hill Book Co. Inc., New York.

24. Wilson, W. H., T. K. Perkins, and J. H. Striegler, 1980, "Casing Buckling Studies Lower Cementing Costs," World $0 i 1$, September, pp. 63-67.

25. Wooley,G. R., S. A. Christman, J. G. Crose, 1977, "Strain Limit Design of $13-3 / 8$ inch $N-80$ Buttress Casing," J. of Petroleum Technology, pp. 355-359.

26. Wooley, G. R., 1980, "Well-Bore and Soil Thermal Simulation for Geothermal Well: Comparison of GEOTEMP Predictions to Field Data and Evaluation of Flow Variables," SAND79-7116, Sandia National Laboratories, Albuquerque, New Mexico, March. 


\section{APPENDIX A}

Nomenclature

A

D

E

e

I

L

$\ell$

$M_{b}, M_{R}$

P, Pcr, Pe

$r_{i}, r_{0}$

$r_{g}$

$v, v_{R}$

$y, y_{\max }$

$y^{\prime}, y^{\prime \prime}$

$\Delta T, \Delta T_{c r}$

$\alpha$

$\delta(P), \delta(T)$

$\delta_{1}(y), \delta_{2}(y)$
- casing cross-sectional area $\left(L^{2}\right)$

- outside casing diameter (L)

- modulus of elasticity (M/tL)

- gap between casing and drilihole (L)

- moment of inertia $\left(L^{4}\right)$

- total unsupported length (L)

- unsupported length between fixed end and point of contact with wall (L)

- moment at point $b$ and reaction moment $(M / t)$

- axial load, axial load when Euler buckling initiated, and reaction load (M/tL)

- inside and outside casing radius (L)

- radius of gyration (L)

- shear force applied at wall contact and reaction shear force $(M / t L)$.

- casing deflection and maximum casing deflection (L)

- first and second derivatives, respectively

- temperature change and temperature change when Euler buckling initiated (T)

- linear coefficient of thermal expansion $\left(T^{-1}\right)$

- axial load and thermal load displacements

- deflection displacements before and after wall contact ( $L$ ) 
$\sigma_{a},\left(\sigma_{b}\right)_{\max }$

$\sigma_{w} /, \sigma_{w} / 0$

$\sigma t$

$\sigma y$
- axial stress and maximum bending stress $(M / t L)$

- total casing stress with and without wall contact $(M / t L)$

- total casing stress (M/tL)

- yield stress $(M / t L)$ 


\section{APPENDIX B \\ Derivation of Equations}

Appendix $B$ presents in greater detail the derivations of pertinent equations in the text. The concepts are quite simple, but the algebra can be tedious. The casing shape description and the expression for maximum stress before wall contact are derived first. The casing shape and stress equations after wall contact follow. For clarity, additional equations and figures were added to those presented in the text. They are prefixed with the letter "B."

\section{Differential Equation}

From the free body diagram in Figure $6 \mathrm{~b}$, the following equilibrium criteria must be met:

$$
\begin{aligned}
\boldsymbol{C}_{\Sigma M_{a}} & =M_{R}+M-P_{e}+V=0 \\
\Sigma F_{x} & =P_{R}-P=0 \\
\Sigma F_{y} & =V_{R}-V=0
\end{aligned}
$$

If a section through the beam is taken before point $b$ (Figure $B-1 a$ ) then the following equation results:

$$
A_{\Sigma M_{a}}=M_{R}-M-P_{y}+V_{x}=0
$$


FREE BODY DIAGRAMS OF WELL CASING

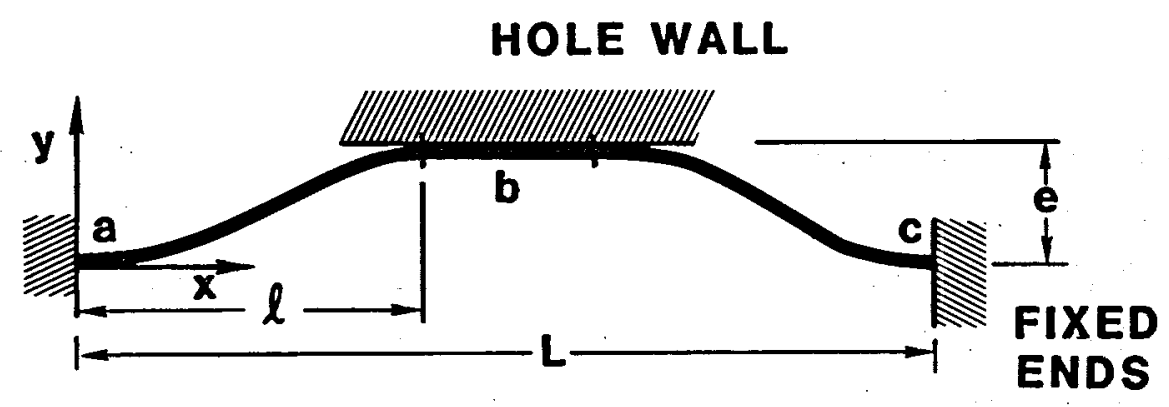

a)
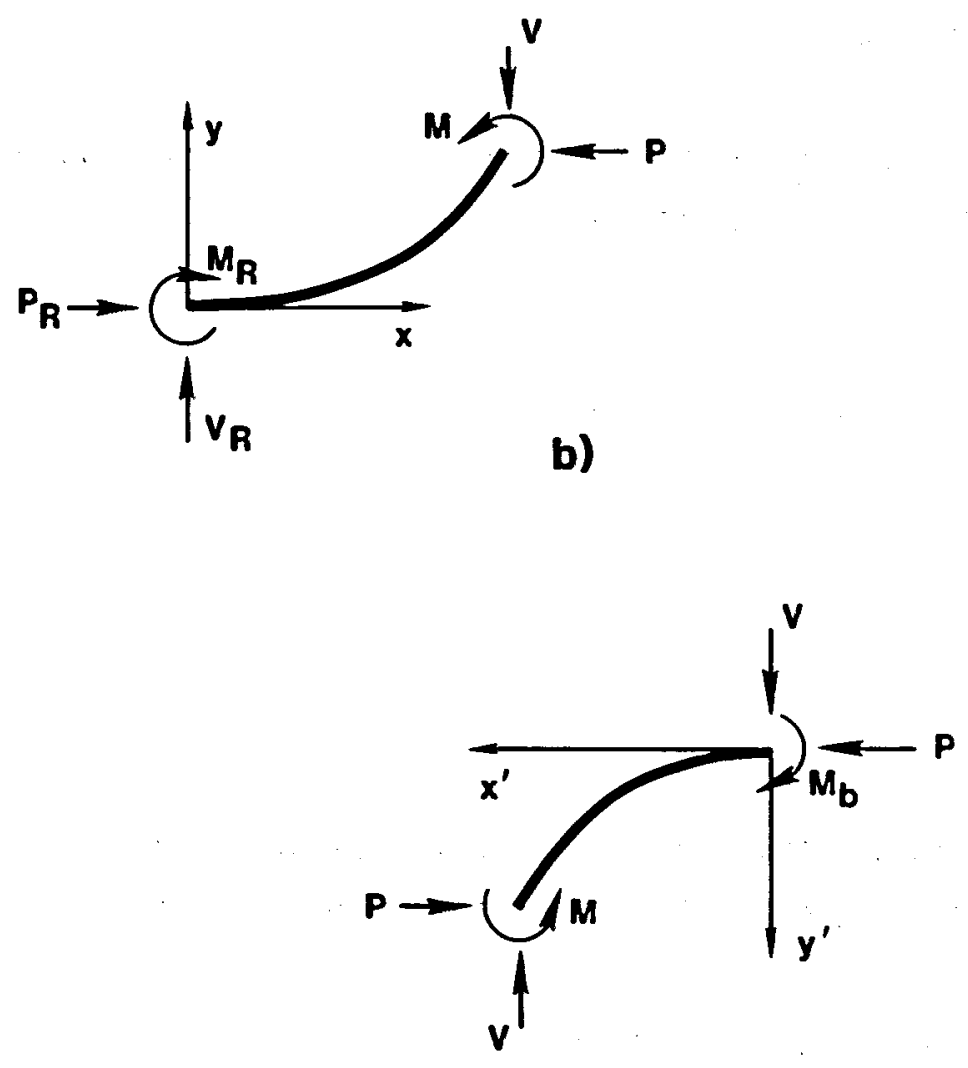

c)

Figure B-1. Supplementary Free Body Diagrams 
By assuming $\left(y^{\prime}\right)^{2}$ is small compared to $y^{\prime \prime}$ in the mathematical expression for curvature, Euler beam theory expresses the moment $M$ as :

$$
M=E I y^{\prime \prime}
$$

This equation applies assuming: 1) $\left(y^{\prime}\right)^{2}$ is smal1, 2) Hook's law applies, 3) $E$ is the same for tension and compression, 4) a plane section remains plane after bending, and 5) longitudinal fiber lengths do not change. Substituting for $M$ :

$$
y^{\prime \prime}+\frac{P_{y}}{E I}=\frac{M_{R}+V x}{E I}
$$

The solution of the differential equation is

$$
y=A \cos K x+B \sin K x+\frac{1}{K^{2}}-\left(\frac{M_{R}+V x}{E I}\right)
$$

where

$$
K^{2}=P / E I
$$

From Figure $6 a$ it is evident the fixed-end boundary conditions at point a are:

$$
\begin{aligned}
& x=0, y=0 \\
& x=0, y^{\prime}=0
\end{aligned}
$$

Consequentry:

$$
y=\frac{M_{R}}{P}(1-\cos K x)+\frac{V}{P}\left(x-\frac{1}{K} \sin K x\right)
$$




\section{Before Wal1 Contact}

Critical temperature. Before wall contact, the shear force (V) is zero. Consequently the casing takes the shape of a raised cosine function:

$$
y=\frac{M_{R}}{P}(1-\cos K x)
$$

The deflection and slope at point $c$ is also specified and establishes two additional boundary conditions:

$$
\begin{aligned}
& x=L=2 l, y=0 \\
& x=L=2 l, y^{\prime}=0
\end{aligned}
$$

Both boundary conditions establish a further restriction on $k$ :

$$
K=2 \pi m / L, \quad m=0,1,2, \ldots
$$

Equating the two expressions for $k$ and letting $m=1$ results in:

$$
P=4 \pi^{2} E I / L^{2}
$$

For a thermally induced load:

$$
P_{c r}=A E \alpha \Delta T
$$

Substituting for the load $P$ and solving for $\Delta T$ :

$$
\Delta T=\frac{4 \pi^{2} I}{L^{2} A \alpha}
$$

Maximum Stress. The total stress $\left(\sigma_{t}\right)$ after the casing has buckled equals (neglecting ovalation stresses):

$$
\sigma_{t}=\sigma_{a}+\left(\sigma_{b}\right)_{\max }
$$

The expression of $\sigma_{a}$ is: 


$$
\sigma_{a}=P_{c r} / A=E \alpha \Delta T_{c r}=\text { constant }
$$

For a long, slender casing it is reasonable to assume $\sigma_{b}=M c / I$ while stresses remain below yield. From equation (B-2) where $v=0$ :

$$
\begin{aligned}
M & =M_{R}-P_{y} \\
& =M_{R} \cos K x \quad \text { (using } 4 \text { ) }
\end{aligned}
$$

The maximum bending stress $\left(\sigma_{b}\right)_{\max }$ occurs at the end points when:

$$
\left(\sigma_{b}\right)_{\max }=M_{R} r_{0} / I
$$

The restraining moment after buckling $\left(M_{R}\right)$ is found by the procedure outlined by Boles and Whiner (1960). The thermally induced length change $(\delta(T))$ must equal the sum of the axial load deformation $(\delta(P))$ and the casing deflection $(\delta(y))$ (Figure $B-2 a)$ :

$$
\delta(T)=\delta(P)+\delta_{1}(y)
$$

The expressions for the thermal and axial displacements are

$$
\begin{aligned}
& \delta(T)=\alpha \Delta T L \\
& \delta(P)=P_{C r} L / A E=\text { constant }
\end{aligned}
$$

The deflection displacement is equivalent to (where as is measured along the casing):

$$
\begin{aligned}
\delta_{1}(y) & =\int_{0}^{L}(d s-d x) \\
& =\int_{0}^{L}\left[1-\left(y^{\prime}\right)^{2}\right] d x
\end{aligned}
$$

49 
Using a Taylor expansion of the integrand and neglecting higher order terms results in:

but

$$
\delta_{1}(y)=\int \frac{1}{2}\left(y^{\prime}\right)^{2} d x
$$

$$
y^{\prime}=\frac{-M_{R} K}{P} \sin K x
$$

hence

$$
\delta_{1}(y) \simeq\left(\frac{M_{R} K}{2 P}\right)^{2} L
$$

Substituting (10), (11), and (13) into (9) and solving for M:

$$
M_{R}=\frac{2 P}{K}\left(\alpha \Delta T-\frac{P}{A E}\right)^{1 / 2}
$$

As argued in the report, once buckling has occurred, $\delta(T)$ is entirely absorbed by $\delta(y)$; hence $\delta(P)$ remains constant. Consequently o remains at the critical buckling stress. Substituting $(B-4)$ into $(B-5)$ yields:

$$
M_{R}=\frac{A E \alpha \Delta T_{c r}}{\pi}\left[\left(\alpha\left(\Delta T-\Delta T_{c r}\right)\right]^{1 / 2}\right.
$$

Inserting equation (14) into (8) and evaluating I for a pipe yields:

$$
\left(\sigma_{b}\right)_{\max }=A E \alpha \Delta T_{c r}\left[\alpha\left(\Delta T-\Delta T_{c r}\right)\right]^{1 / 2} 4 L r_{0} / \pi\left(r_{0}^{2}+r_{i}^{2}\right)
$$

Substituting $(B-6)$ and (7) into (6) results in:

$$
\sigma_{t}=E \alpha \Delta T_{c r} \quad\left\{1+\frac{4 L r_{0}}{\pi\left(r_{0}^{2}+r_{i}^{2}\right)}\left[\alpha\left(\Delta T-\Delta T^{l / 2}\right)\right]\right\}
$$




\section{DISPLACEMENT RELATIONSHIPS}

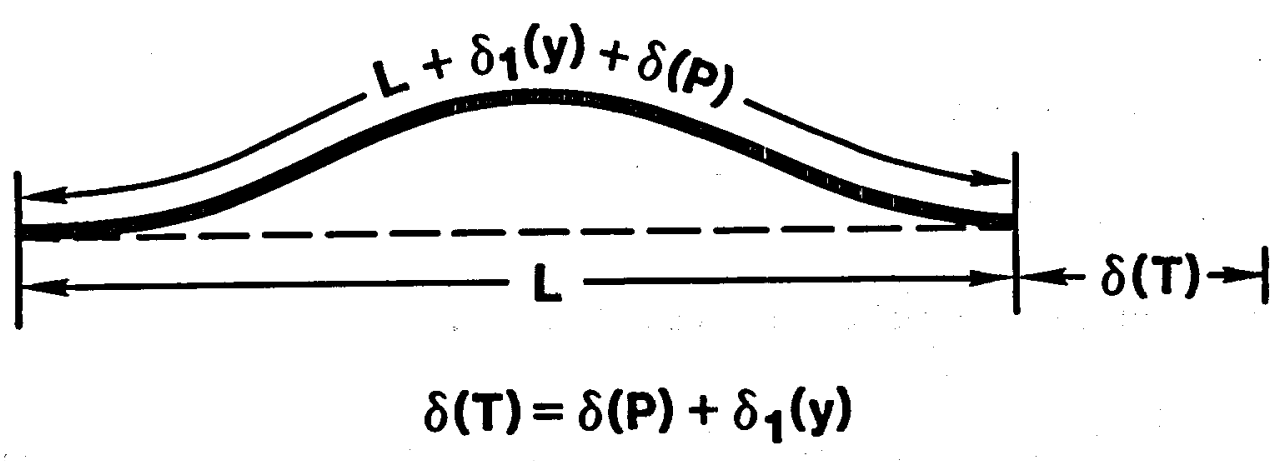

a)

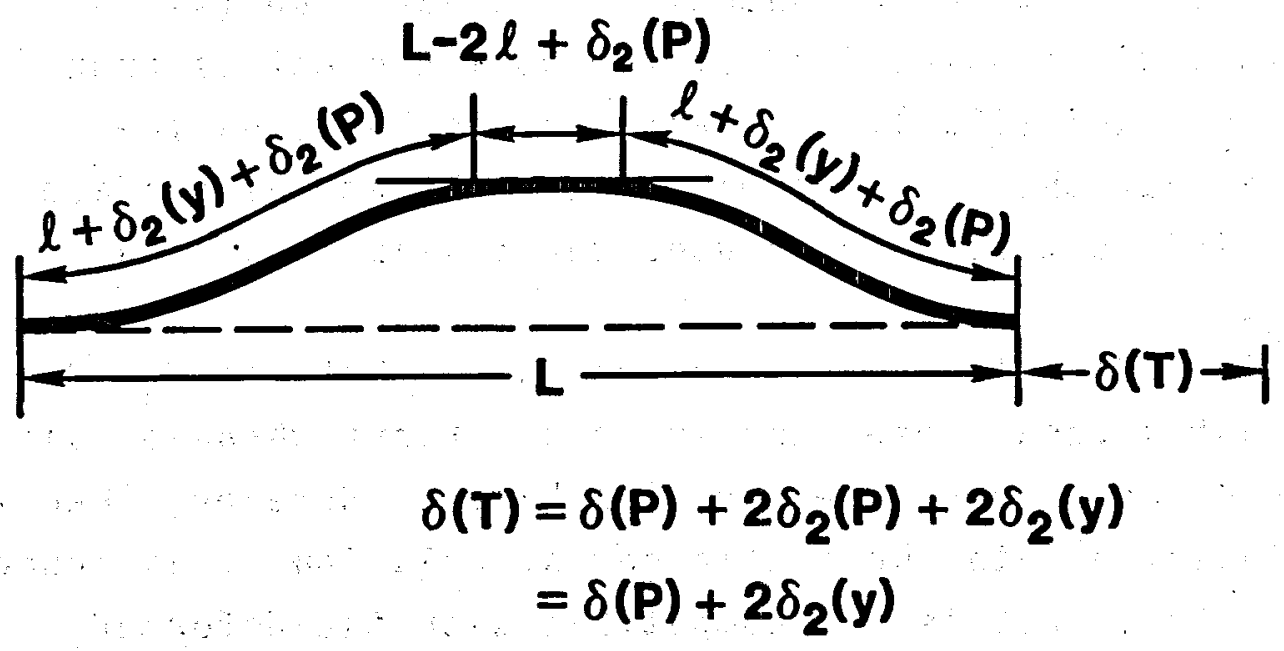

b)

Figure B-2: Thermal, Axial, and Beam Deflection Displacement Relationships. 


\section{After Wall Contact}

Casing Shape. After wall contact occurs the fixed end boundary conditions at point "a" still hold and thus equation (2) is applicable. Two new boundary conditions at the point of wall contact are:

$$
\begin{aligned}
& x=\ell, y=e \\
& x=\ell, y^{\prime}=0
\end{aligned}
$$

The fourth boundary condition establishes:

$$
y^{\prime}=\frac{M}{P}\left(K^{\prime} \sin K \ell\right)+\frac{V}{P}\left(1-\cos K^{\prime} \ell\right)
$$

where

$$
K^{\prime}=P / E \ell
$$

The plausibility of a concentrated shear load (V) as opposed to a distributed load at the wall contact is argued in Crandall and Dahl (1959). The argument is based on the assumption that the beam-column is straight at the surface contact. This situation precludes the possibility of a moment $M_{b}$.

Equation (3) establishes a relationship between $M_{R}, V$ and $P$ (or $K$ ) but several cases are evident. First whenever $s$ in $K l$ and $1-\cos K l$ equal zero the equation holds. However, when this case is inserted into the static moment relation it is found $M_{R}=-M_{b}$. This fact is not compatible with the deformed casing shape after wall contact (Figure $8 b$ ).

Another possibility is where $M_{R}$ and $1-\cos K l$ equal zero. (After wall contact, the shear force ( $V$ ) is nonzero in equation (3).) Because $M_{b}$ is assumed to equal zero it is possible to show $M_{R}=0$ also. 
The plausibility of this fact can be seen by examining the free body diagram in Figure $B-1 C$. Figure $B-1 C$ is simply the mirror image of Figure $B-1 b$ which was used to obtain equation $(B-2)$. Only the moment $M_{R}$ is missing. Another heuristic argument is found by assuming Figures $B-1 b$ and $B-1 C$ are divided at the change in curvature. At the point of counterflexure, $M=0$. A sum of moments in Figure $B-1 c$ results in $\mathrm{Pe}=\mathrm{Vl}$. Applying this relationship to the moment relationship of equation $(B-1)$ where $M=0$ results in $M_{R}=0$. Therefore, if a straight section exists in the casing at the wall contact, both end moments are replaced with concentrated shear forces (v).

From the condition $M_{R}=0$ and $1-\cos K^{\prime} x=0$ in equation (3), the shape of the casing between points "a" and "b" is:

$$
y=\frac{V}{P}\left(x-\frac{1}{K}, \sin K^{\prime} x\right)
$$

where

$$
K^{\prime}=2 \pi / \ell
$$

At the moment of contact $\ell=L / 2$ or $K^{\prime}=4 \pi / L$. Use of the third boundary condition results in $\mathrm{Pe}=V \ell$.

In order to make comparisons between equation (4) and (B-7) it is desirable to define $K=2 \pi / L$ in which case equation $(B-7)$ becomes:

$$
y=\frac{V}{p}\left(x-\frac{1}{2 K} \sin 2 K x\right)
$$

Up until wall contact, the casing shape was described by the cosine expression (4). After contact, equation (16) requires an instantaneous change in casing shape. The predicament results from the assumption of a straight section at the instant of contact. There is actually a transition zone where both a moment and a shear force exist, but the 
significance of the casing moment should gradually decrease after wall contact.*

Because of the existence of a transition zone where both a moment and a shear (or more realistically, a distributed force) exist simultaneously, a more detailed analytic solution is required. However, an alternative is to describe the casing shape as a "split cosine bell" in the transition zone. The split-cosine formulation is developed in a subsequent section.

Variable Length (l). The variable length $(l)$ is shown in Figures $B-1 a$ and $B-2 b$. It is the length between the fixed end and the point of wall contact. The length $(l)$ shortens as the casing segment against the wall lengthens due to increased deformation. An expression for the variable length (l) pertaining to equation (16) is found from the condition that the thermal displacement $(\delta(T))$ equals the sum of the axial load displacement $(\delta(P))$ and twice the casing deflection $\left(\delta_{2}(y)\right)$ (Figure $\left.B-2 b\right)$ :

$$
\delta(T)=\delta(P)+2 \delta_{2}(y)
$$

The expressions for displacements are equations (10), (11), and (12) as before. Substituting equation (16) into equation (12) results in:

$$
\delta_{2}(y)=\frac{3}{4}\left(\frac{v}{P}\right)^{2} \ell
$$

₹ The importance of the moment could increase again if enough thermal elongation occurred such that the casing began to buckle in the region of wall contact. (With a thin-walled. pipe it is more likely that plastic deformation such as kinking or collapse would occur before assuming a higher buckling mode.) The buckling phenomenon is easily visualized if a flexible bar or note card is buckled against. a solid surface. 
It is important to note the difference in the casing deflection between equations (13) and ( $B-9)$. By combining equations (13) and $(B-5)$ it is easily shown:

$$
\delta_{1}(y)=\alpha L\left(\Delta T-\Delta T_{c r}\right)
$$

The expression for casing deflection after wall contact is given by $(B-9)$ but $V=e P / l$; hence:

$$
\delta_{2}(y)=\frac{3}{4} \frac{e^{2}}{l}
$$

At the instance of wall contact, $e=y_{\max }=2 M_{R} / P$. Expressing $M_{R}$ by $(B-5)$ and substituting into $(B-11)$ yields:

$$
\delta_{2}(y)=\alpha L\left(\Delta T-\Delta T_{c r}\right) 6 / \pi^{2}
$$

Equations $(B-10)$ and $(B-12)$ differ by the factor $6 / \pi^{2}$.

A relationship for the variable length is found by substituting $(10),(11)$, and $(B-11)$ into $(B-8)$ which yields:

$$
a \Delta T L=\frac{P}{A E}+2\left(\frac{3}{4} \frac{e^{2}}{l}\right)
$$

but

$$
P_{C r}=4 \pi^{2} E I L^{2}
$$

Substituting this expression into $(B-13)$, evaluating $I$ and $A$, and solving for $\ell\left(\Delta T>\Delta T_{C r}\right)$ :

$$
\ell_{1}=\frac{3}{2} \mathrm{e}^{2} L /\left[\alpha \Delta T L^{2}-\pi^{2}\left(r_{0}^{2}+r_{i}^{2}\right)\right]
$$

It can be shown $\ell_{1}=\left(12 / \pi^{2}\right) \mathrm{L}$ at the instant of contact rather than $1 / 2 \mathrm{~L}$. 
In the above formulation, it was assumed the displacement from the axial load remained constant $\left(P=P_{c r}\right)$. However, a new critical buckling load exists for the short casing of length ( $l$ ) which is 4 times as great.

$$
P=\frac{4 \pi^{2} E I}{k^{2}}
$$

Friction along the wall could provide a mechanism for this new threshold to be reached. Also if the casing was to assume a higher buckling mode, larger axial loads than the critical load associated with the first buckling mode seemed possible. Consequently, an expression for $\ell$ was derived which permitted an increase in the axial load (P). A quadratic expression results:

$$
l_{2}=\left\{3 e^{2}+\left[9 e^{4}+\alpha \Delta L^{2} \pi^{2}\left(d_{0}^{2}+d_{i}^{2}\right)\right]^{1 / 2}\right\} / 4 \alpha \Delta T L
$$

The load $P$ was expressed as $\pi^{2} E I / \ell^{2}$. This is the initial value of the load $P$. The threshold for the load $P$ would be $4 \pi^{2} E I / \ell^{2}$. The two expressions for $l$, equations $(B-14)$ and $(B-15)$ are compared in Table $B-I$. From the discrepancies in Table $B-1$, it is evident that the length $(l)$ is a likely source of error in the analytical expression for the maximum stress derived below. (Good agreement exists between $(B-16)$ and (17) and will be discussed in a subsequent section.) The approximation for beam deflection displacement $(\delta(y))$ was examined as a possible source of error in the theoretical determination of $l$. The second term in the Taylor expansion of $\delta(y)$ was incorporated but its influence was insignificant as originally assumed.

Maximum stress after wall contact. The total stress $\left(\sigma_{t}\right)$ after the casing has buckled and contacted the wall is expressed by the sum of $\sigma_{a}$ and $\left.\left(\sigma_{b}\right)_{\max }\right)$ (equation 5 ). The expression for $\left(\sigma_{b}\right)_{\max }$ is again $M c / I$. The value for $M$ is 
Table B-I. Comparison of Analytic Results for $13-3 / 8$ inch 54.5 ppf $N-80$ Casing with an Unsupported Length of 1000

$\left(\Delta T_{C r}=71.7^{\circ} \mathrm{F}=22^{\circ} \mathrm{C}\right)$

\begin{tabular}{|c|c|c|c|c|c|c|c|}
\hline $\begin{array}{l}\text { temp } \\
\text { change } \\
\frac{\Delta T}{\Delta T} \text { cr }\end{array}$ & $\begin{array}{c}\text { displacement } \\
\frac{Y_{\max }}{D}\end{array}$ & $\begin{array}{l}\text { hole } \\
\text { gap } \\
\frac{e}{d}\end{array}$ & $\begin{array}{c}\text { constant } \\
\frac{2 l_{1}}{L}\end{array}$ & $\begin{array}{l}\text { ted } 1 \text { er } \\
\frac{\operatorname{var}}{L}\end{array}$ & $\begin{array}{l}\text { split } \\
\frac{2 l_{3}}{L}\end{array}$ & $\begin{array}{l}\operatorname{maximum} \\
\frac{\sigma_{w / 0}}{\sigma_{y}}\end{array}$ & $\begin{array}{l}\text { stress } \\
\frac{\sigma_{w l} l}{\sigma_{y}}\end{array}$ \\
\hline 1.5 & 0.978 & $\begin{array}{l}.250 \\
.500 \\
.750 \\
.978\end{array}$ & $\begin{array}{r}.079 \\
.318 \\
.714 \\
1.215\end{array}$ & $\begin{array}{r}.828 \\
.870 \\
.944 \\
1.044\end{array}$ & $\begin{array}{r}.825 \\
.860 \\
.920 \\
1.000\end{array}$ & .519 & $\begin{array}{l}.300 \\
.411 \\
.486 \\
.745\end{array}$ \\
\hline 2.0 & 1.370 & $\begin{array}{r}.250 \\
.500 \\
.750 \\
1.000 \\
1.370\end{array}$ & $\begin{array}{r}.040 \\
.162 \\
.364 \\
.649 \\
1.214\end{array}$ & $\begin{array}{l}.718 \\
.750 \\
.805 \\
.888 \\
1.073\end{array}$ & $\begin{array}{l}.716 \\
.743 \\
.786 \\
.854 \\
1.000\end{array}$ & .659 & $\begin{array}{l}.344 \\
.709 \\
.602 \\
.660 \\
.659\end{array}$ \\
\hline 4.0 & 2.380 & $\begin{array}{r}.500 \\
.750 \\
1.000 \\
1.500 \\
2.380\end{array}$ & $\begin{array}{r}.054 \\
.120 \\
.214 \\
.048 \\
1.214\end{array}$ & $\begin{array}{r}.520 \\
.547 \\
.587 \\
.713 \\
1.131\end{array}$ & $\begin{array}{r}.517 \\
.538 \\
.571 \\
.671 \\
1.000\end{array}$ & 1.466 & $\begin{array}{l}.839 \\
1.094 \\
1.268 \\
1.362 \\
1.021\end{array}$ \\
\hline
\end{tabular}


found from equation $(B-2)$ where $M_{R}=0$. Expressing y by equation (11) and substituting into (B-2) results in:

$$
M=\frac{V}{K} \cdot \sin K^{\prime} x
$$

The maximum moment will occur at the quarter points: $x / l=1 / 4$ or $x / l=3 / 4$. (This differs from the cosine equation(4) where the maximum bending stress occurs at $x=L / 2$.) Thus:

$\left(\sigma_{b}\right)_{\max }=V r_{0} / K^{\prime} I$

but

$$
\begin{aligned}
V & =P e / l \\
K^{\prime} & =2 \pi / \ell=(P / E I)^{1 / 2}
\end{aligned}
$$

hence

$\sigma_{b}(\max )=\pi E_{0} / 2 l^{2}$

Therefore

$$
\sigma_{t}=E \alpha \Delta T_{c r}+\pi E e r_{0} / 2 l^{2}
$$

where $l$ is described by equation $B-14$ or $B-16$. The use of the numerically determined $\ell$ in equation (19) did improve the correspondence with the numerical results.

It should be noted that an inconsistency exists in the above derivation. The axial load ( $P$ ) increases beyond $P_{c r}$ in the expression of $\ell(B-16)$ while the axial stress cannot exceed $P_{c r} / A$ in equation (19). Replacing $\Delta T_{c r}$ with $\Delta T$ in (19) results in the total stress $\left(\sigma_{t}\right)$ increasing much faster with increasing $\Delta T$. The resulting values do not correspond with the numerical results and thus equation (19) was not altered. 
found from equation $(B-2)$ where $M_{R}=0$. Expressing y by equation (11) and substituting into (B-2) results in:

$$
M=\frac{V}{K}, \sin K^{\prime} x
$$

The maximum moment will occur at the quarter points: $x / \&=1 / 4$ or $x / l=3 / 4$. (This differs from the cosine equation(4) where the maximum bending stress occurs at $x=L / 2$.) Thus:

$$
\begin{aligned}
\left(\sigma_{b}\right)_{\text {max }} & =V r_{0} / K, I \\
\text { but } & \\
V & =P e / l \\
K^{\prime} & =2 \pi / l=(P / E I)^{1 / 2}
\end{aligned}
$$

hence

$$
\sigma_{b}(\max )=\pi \operatorname{Eer}_{0} / 2^{2}
$$

Therefore

$$
\sigma_{t}=E \alpha \Delta T_{c r}+\pi E_{0} / 2 l^{2}
$$

where $\ell$ is described by equation $B-14$ or $B-16$. The use of the numerically determined $l$ in equation (19) did improve the correspondence with the numerical results.

It should be noted that an inconsistency exists in the above derivation. The axial load ( $P$ ) increases beyond $P_{C r}$ in the expression of $\ell(B-16)$ while the axial stress cannot exceed $P_{c r} / A$ in equation (19). Replacing $\Delta T_{c r}$ with $\Delta T$ in (19) results in the total stress $\left(\sigma_{t}\right)$ increasing much faster with increasing $\Delta T$. The resulting values do not correspond with the numerical results and thus equation (19) was not altered. 
Figure 10a demonstrates the two analytical expressions (3) and (16) do not agree in shape when contact occurs. There is a transition period from equation (3) and (16). Rather than resort to a more complicated mathematical description of the casing during the transition, the casing shape was described as a split-cosine bell. One must assume the end moments continue to act after wall contact. Summing moments about an end of the free body diagram yields:

$$
M_{R}=P e / 2
$$

The following shape description results when the end moment expression is substituted into (3):

$$
y=\frac{e}{2}(1-\cos k x)
$$

An identical expression pops out from equation (2) if $V$ is set equal to zero and the boundary conditions applicable after wall contact are applied.

Length description $\ell_{3}$. The derivation for the description of length $\left(l_{3}\right)$ follows the steps outlined in the previous section. Equation $(B-8)$ describes the thermal displacement $(\delta(T))$. Equation $(B-13)$ describes the beam displacement $(\delta(y))$. The axial displacement term corresponds to (11) except that the axial load is allowed to increase beyond $P_{c r}$. It follows that $l_{3}$ is represented by:

$$
\ell_{3}=(\pi \mathrm{e})^{2} /\left(8 \mathrm{~L} \alpha \Delta \mathrm{T}-\frac{\mathrm{P}}{\mathrm{AE}}\right)
$$

If the expression for the load $P=\pi^{2} E I / \ell^{2}$ is substituted in $(B-18)$ and the resulting quadratic is solved for $l_{3}$, then:

$l_{3}=\left\{(\pi \mathrm{e}) A^{2}+\left[(\pi \mathrm{e})^{4} A^{2}+256 \mathrm{~L}^{2} \pi^{2} I A \alpha \Delta T\right]^{1 / 2}\right\} 16 L A \alpha \Delta T$ 
Values of $\ell_{3}$ for various temperature changes $(\Delta T)$ and hole gaps are tabulated in Table B-I. The agreement between (17) and $(B-19)$ is very good.

Maximum stress. The total maximum stress $\left(\sigma_{t}\right)$ is expressed by equations (6), (7), and (8) except that $M_{R}$ is equivalent to Pe/2 (B-17). An expression identical to (19) resuits. 

Distribution:
TID-4500-R66-UC-66C (507)
Tom Anderson
Venture Innovations
P. 0. Box 35845
Hous ton, TX 77035
EJ Bingman
hell 0il Company
Iwo Shell Plaza
P. 0. Box 2099
Houston, TX 77001
Larry Diamond
Dyna-Drill
P. 0. Box C-19576
Irvine, CA 92713
John E. Fontenot
NL Petroleum Services
P. 0. Box 60087
Houston, TX 77205
Or. Melvin Friedman
Professor of Geology
Center for Tectonophysics and Dept. of Geology

Texas A\&M University

College Station, TX 77843

Tom Turner

Phillips Petroleum Company Geothermal 0perations

655 East 4500 South

Salt Lake City, UT 84107

Jim Kingsolver

Geothermal Operations

Smith Tool

P. 0. Box C- 19511

Irvine, CA 92713

James W. Langford

Security Division

Dresser Industries, Inc.

P. 0. Box 24647

Dallas, TX 75224

Harvey E. Mallory

P. 0. Box 54696

Tulsa, OK 74155
Gene Polk

NL Baroid

6400 Uptown Blvd. NE, $365 \mathrm{~W}$

Albuquerque, NM 87110

Del E. Pyle

Union Geothermal Division

Union $0 i 1$ Co. of California

Union oil Center

Los Angeles, CA 90017

John C. Rowley

Los Alamos National Labs

Mail Stop 570

Los Alamos, NM 87545

William D. Rumbaugh

Research and Development

0 tis

P. 0. Box 34380

Dallas, TX 75234

Dwight Smith

Haliiburton

Drawer 1431

Duncan, OK 73533

Tom Warren

Amoco Production Company

Research Center

P. 0. Box 591

Tulsa, OK 74102

Ed Martin

Superior 0ii

Eastern Division

P. 0. Box 51108 OCS

Lafayette, LA 70505

B. J. Livesay

129 Liverpool

Cardiff, CA 92007

U. S. Department of Energy

Geothermal Hydropower

Technologies Division

Forrestal BIdg. CE 324

1000 Independence Ave. S.W. Washington, D.C. 20585

Attn: J. Bresee

D. Clements

R. Toms

D. Allen 
W. P. Grace, DOE/AL

Nuclear \& Geosciences Division

$\begin{array}{ll}1500 & \text { W. Herrmann } \\ 1510 & \text { D. B. Hayes } \\ 1520 & \text { T. B. Lane } \\ 1521 & \text { R. D. Krieg } \\ 1522 & \text { T. G. Priddy } \\ 1522 & \text { R. P. Rechard (10) } \\ 1522 & \text { K. W. Schuler (5) } \\ 1523 & \text { R. C. Reuter } \\ 1524 & \text { W. N. Sul1ivan } \\ 1530 & \text { L. W. Davison } \\ 1540 & \text { W. C. Luth } \\ 3141 & \text { L. J. Erickson (5) } \\ 3151 & \text { W. L. Garner (3) } \\ 9000 & \text { G. A. Fowler } \\ 9700 & \text { E. H. Beckner } \\ 9730 & \text { W. D. Weart } \\ 9740 & \text { R. K. Traeger } \\ 9741 & \text { J. R. Kelsey (10) } \\ 9741 & \text { B. C. Caskey (5) } \\ 9743 & \text { H. C. Hardee } \\ 9746 & \text { B. Granoff } \\ 9747 & \text { P. J. Hommert } \\ 9750 & \text { V. L. Dugan } \\ 9760 & \text { R. W. Lynch } \\ 9770 & \text { G. E. Brandvold } \\ 8214 & \text { M. A. Pound } \\ & \end{array}$

